Portland State University

PDXScholar

$1-1-2010$

\title{
Globalization; But Under What conditions? -- The Case of the E.U.
}

Michaelangelo Anastasiou

Portland State University

Follow this and additional works at: https://pdxscholar.library.pdx.edu/open_access_etds Let us know how access to this document benefits you.

\section{Recommended Citation}

Anastasiou, Michaelangelo, "Globalization; But Under What conditions? -- The Case of the E.U." (2010). Dissertations and Theses. Paper 432.

https://doi.org/10.15760/etd.432

This Thesis is brought to you for free and open access. It has been accepted for inclusion in Dissertations and Theses by an authorized administrator of PDXScholar. Please contact us if we can make this document more accessible: pdxscholar@pdx.edu. 
Globalization; But Under What Conditions? The Case of the E.U.

by

Michaelangelo Anastasiou

A thesis submitted in partial fulfillment of the requirements for the degree of

\author{
Master of Arts \\ in \\ Sociology
}

Thesis Committee:

Veronica Dujon, Chair

Melissa Thompson

Michael Toth

Portland State University

(C)2010 


\begin{abstract}
The present study explores the relationship between trust placed in national institutions and opinion of globalization. A secondary data analysis is conducted using data collected by the European Commission in a 2004 Eurobarometer survey of European Union (EU) citizens on various issues regarding the EU, globalization and national challenges. A prominent theme in the literature is that, in recent times, globalization has had the effect of compromising the sovereignty of nation-states. This has generated a backlash of nationalistic attitudes wherein globalization is posited in opposition to the nation-state. This surge in nationalism has reinforced a culture wherein any external force that has the capacity to compromise or merely challenge national sovereignty is deemed undesirable. The EU represents a unique response to the phenomenon of globalization. It is the only economic bloc that attempts to manage globalization and mitigate its negative effects through the promotion of a free market system that is actively reinforced by political and social transnational unity. By assessing EU citizens' opinion of globalization and its relation to national attachment, one can investigate whether in living in a system of shared national sovereignty, which attempts to actively manage globalization, one experiences globalization not as an external invasive force, but as an integral component of the nation-state.
\end{abstract}




\section{DEDICATION}

The present work is dedicated to the following people for providing a stable, enjoyable and stimulating social environment that enabled me to make it through the routine and constant work of the past two years: My family, including Theodora, Harry and Anastis for providing unequivocal support, unconditional love and constant amusement; My girlfriend, Bria, for her love, support, for making every single day of my life more interesting and stimulating and for being a stable tapas partner for Toro Bravo! Lastly, I would also like to dedicate this work to the following furry little felines that have made my days lighter through their love and silliness: Bella, Zorba and Black Kitty, I envy your lack of consciousness! 


\section{ACKNOWLEDGEMENTS}

Knowledge, productivity and creativity can never be abstracted from their social and cultural contexts. A work is a composite of the sum of its social constituents. The present work could not be made possible without the guide, insight and opportunities provided by the following people and institutions: Professor Veronica Dujon, for chairing my thesis committee, inspiring me and for challenging me and pushing my theoretical potential beyond my perceived limits; Professor Melissa Thompson for providing diligent methodological guide, encouragement and support; Professor Michael Toth for providing a foundational approach and introduction to sociological theory (consciousness, structure and emergence; membership, order and meaning!) and for broadening my theoretical horizons; My father, Professor Harry Anastasiou, whose teachings and life experiences inspired this work and helped me understand the phenomenon of nationalism and the importance of the European Union; The Sociology Department and all its staff and faculty for providing instruction and academic support and Portland State University for providing an institutional foundation for the Sociology Department and its academic culture. 


\section{TABLE OF CONTENTS}

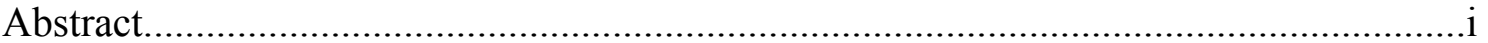

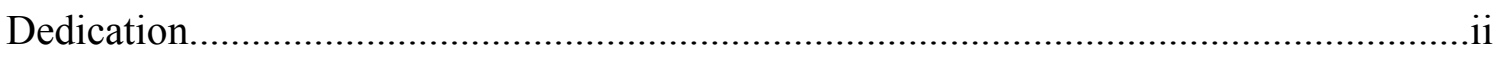

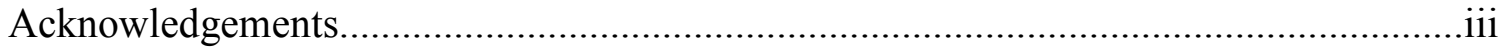

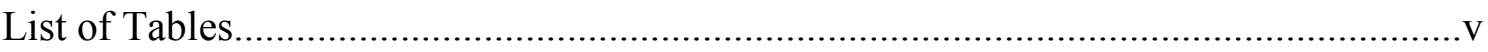

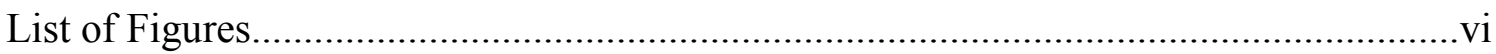

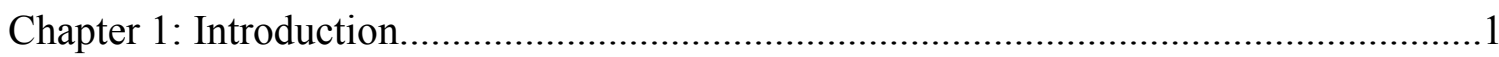

Chapter 2: Review of Literature and Definition of Concepts..............................................

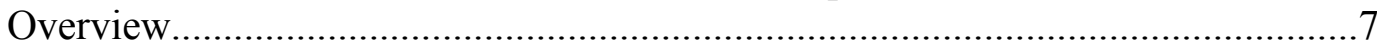

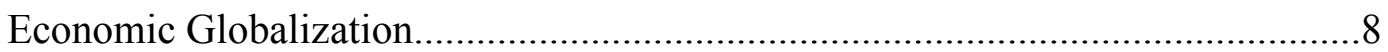

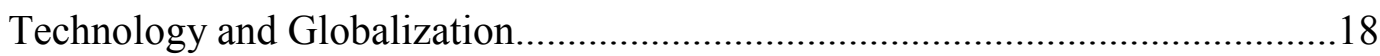

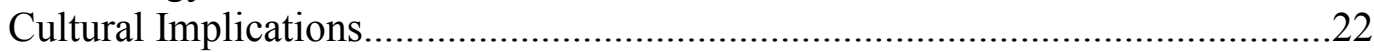

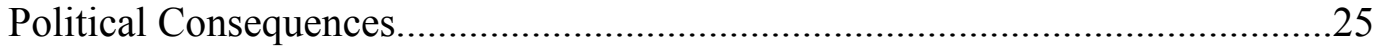

National Institutions, National Consciousness and National Sovereignty............27

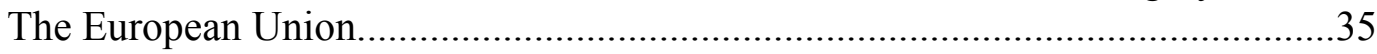

Determinant Factors of Opinion of Globalization................................................42

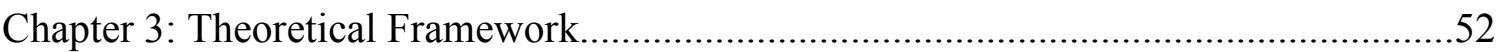

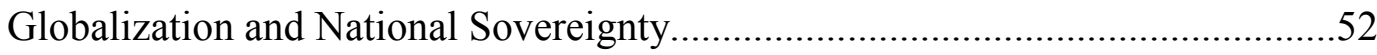

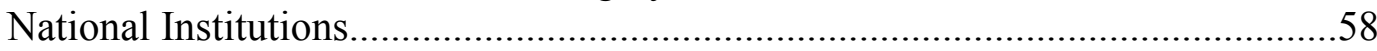

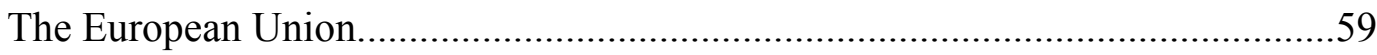

Reasons for Decreasing Levels of Nationalism.................................................67

The End of Nationalism? .............................................................................

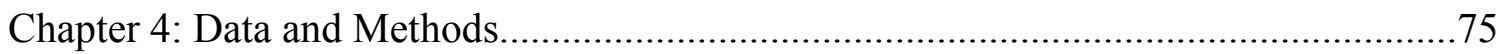

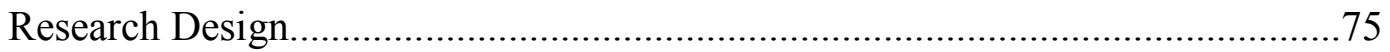

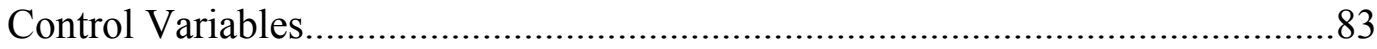

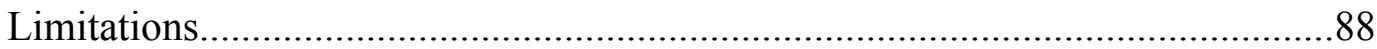

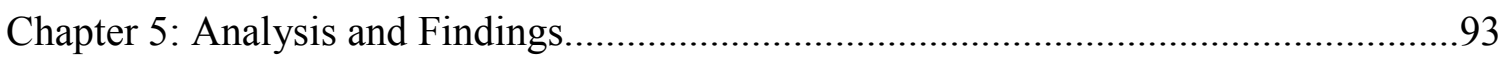

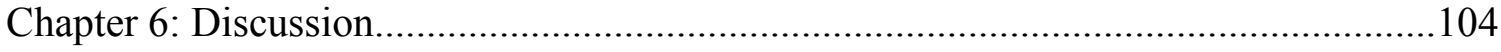

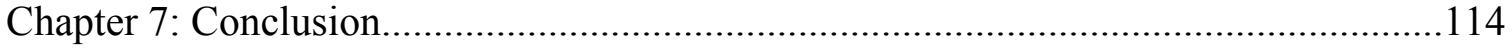

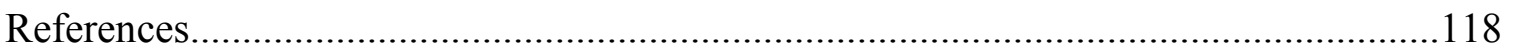

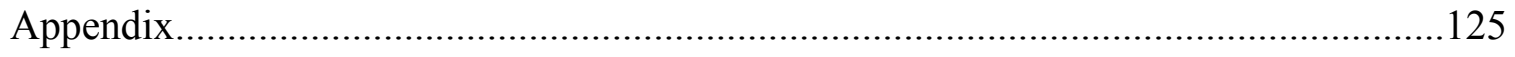




\section{LIST OF TABLES}

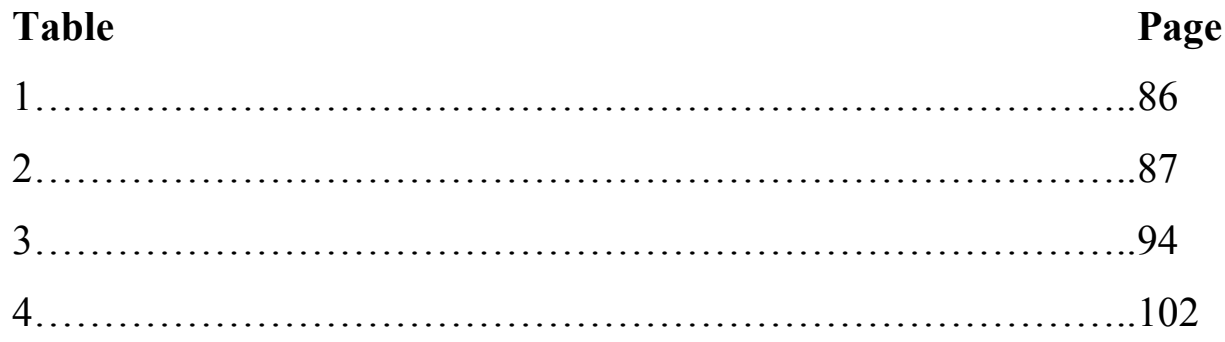




\section{LIST OF FIGURES}

Chart Page

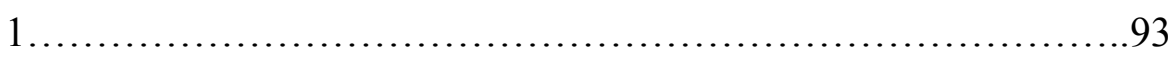

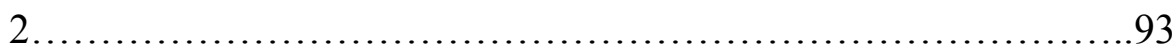




\section{CHAPTER 1: Introduction}

A prominent theme in the literature is that, in recent times, globalization has had the effect of compromising the sovereignty of nation-states (Habermas 1998a; Habermas 1998b; Falk 1999; Giddens 2000; Sassen 2006). This has generated a backlash of nationalistic attitudes in which globalization is posited in opposition to the nation-state (O’Rourke and Sinnott 2001; Rankin 2001; Mayda and Rodrik 2005). This surge in nationalism has reinforced a culture wherein any external force that has the capacity to compromise or merely challenge national sovereignty is deemed undesirable. The implications of these phenomena are of global significance. Reactionary nationalism not only reduces nation-states' capacity to cooperate on the international level and to collectively address the global challenges of the $21^{\text {st }}$ century, but can also contribute to international conflict.

Historically, nationalism as a world view has been considerably salient and pervasive. This is evident in the fact that nationalism has greatly contributed to both national and international conflict. Most wars in the past two hundred years have been fought in the name of the nation. However, since the advent of post-modernity, globalization has challenged, redefined and reconfigured nationalism and the nation-state (Habermas 1998b; Falk 1999). As Castell points out, "Economies throughout the world have become globally interdependent, introducing a new form of relationship between economy, state, and society, in a system of variable geometry" (Castell 1996:1).

Although nationalism has retained its salience, it has taken on a more implicit nature while, nonetheless, continuing to contribute to global political and social turmoil. This is manifested in various ways. It is, for one, reflected in nation-states' incapacity to 
cooperate on global issues such as climate change. The recent Copenhagen accords on climate change serve as proof. The negotiations resulted in a series of weak and marginally impacting agreements, handicapped by an overarching consensus that the sovereignty of nation-states would in no way be infringed upon (United Nations 2009). Nationalism's contribution to social conflict is also reflected in national citizens' opposition to and prejudice against immigrants. Evidence of this is Switzerland's recent ban of minarets and the campaign in support of the legislation - a highly racist campaign tainted with intolerance and politically incorrect imagery and mottos (Euronews 2009). Perhaps nationalism's most belligerent manifestation is in situations where the potential for military confrontation and regional instability is exacerbated, as in the case of the United States' recent confrontation with Iran. In light of these realities it is essential to thoroughly study and address the relationship between national attachment and globalization.

Several scholars have raised awareness to the issue of the need for supranational institutions and processes (Habermas 1998b; Falk 1999; Giddens 2000; Sassen 2006). Their basic premise is that the challenges put forth by globalization cannot be managed by the traditional institution of the nation-state. Global issues and challenges require global and supranational coordination. As Habermas asserts,

"We can no longer view the world economy as an 'international' system of exchange in which nation-states participate as important actors, buttressed by their respective economics and competing with one another through foreign trade channels. Instead, the economy's globalization creates a transnational system that blurs the boundaries between domestic and foreign trade" (Habermas 1998a:3) 
The recent economic collapse of 2008 serves as evidence to this assertion wherein economic deregulation and Wall Street's speculative business and finance practices had the effect of driving the global economy into a recession. The question raised by economists, pundits and the public around the world was that of how to prevent such crises from reoccurring. Economic regulation was the common sense answer. However, what is difficult to address is how to implement economic standards that are congruent between nation-states in order to prevent malevolent economic practices in one country from adversely affecting the economies of others. Such efforts require the implementation of supranational structures, institutions and procedures.

There have been marginal efforts in this respect. For example, following the financial crisis of 2008, the European Parliament and the Obama administration led a cooperative effort to end tax havens (CBS News 2009; European Parliament 2009). Chrysler's recent merger with Italian automaker Fiat, a process mediated by the U.S. government, also reflects this shift toward supranational cooperation (Jackson 2009). Keenly aware of the need for business practices that are congruent with the global challenges of the $21^{\text {st }}$ century, as wells as the global need for fuel efficient technology, the Obama administration reached out to Fiat, a company highly successful in both respects. Moreover, there has been an increasing trend toward inter-governmental cooperation in recent years, albeit mostly in respect to economics. Examples include international agreements such as The North American Free Trade Agreement (NAFTA), and businesses and regional organizations such as the Organization of Petroleum Exporting Countries (OPEC) and the South Asian Association for Regional Cooperation 
(SAARC). However, the only example of supranational decision-making processes being comprehensively implemented and institutionalized is that of the European Union (EU), wherein cooperation and integration occurs on the social, political and economic level.

The EU represents a unique response to the phenomenon of globalization. It is the only economic bloc that attempts to manage globalization and mitigate its negative effects through the promotion of a free market system that is actively reinforced by political and social transnational unity. The unique structure of the EU, the only supranational organization in the world, poses a challenge as well as an opportunity for research examining the relationship between national attachment and opinion of globalization. The fact that its current member states, after fighting two world wars against one another, are able to cooperate on the political, social and economic level in a system of shared sovereignty, renders it a case of academic interest. By assessing EU citizens' opinion of globalization and its relation to national attachment, one can investigate whether in living in a system of shared national sovereignty, which attempts to actively manage globalization, one experiences globalization not as an external invasive force, but as an integral component of the nation-state. The present study explores the relationship between trust placed in national institutions and opinion of globalization. A secondary data analysis is conducted using data collected by the European Commission in a 2004 Eurobarometer survey of EU citizens on various issues regarding the EU, globalization and national challenges.

Throughout the study, various dimensions, aspects, implications and definitions of globalization are explored. For methodological purposes, the Eurobarometer's definition 
of globalization is used in the Analysis and Findings section. The Eurobarometer defines globalization as the opening up of all economies which leads to the creation of a truly world market (Eurobarometer 2004). The findings will be interpreted through the lens of this definition, which captures the neo-liberal economic dimension of globalization because this is the definition used during the Eurobarometer survey interviews which generated the data that is analyzed. The participants were provided with this definition before answering questions related to globalization. It is therefore essential, from a methodological standpoint, to interpret the data using the same definition of globalization that generated them in the first place. However, the phenomenon of globalization, as elucidated in the present study, is one of extreme complexity and multidimensionality. For this reason it is prudent to revert to a more comprehensive and nuanced conception of globalization in the Discussion section. This will enable a more complex and holistic understanding of the findings.

The study is organized as follows: Chapter 2 includes a review of literature and definitions of concepts. The main areas of focus are globalization, national institutions, the European Union and the determinant factors of opinion of globalization. Chapter 3 delineates the theoretical framework, from which the appropriate methodological research approach is generated. Moreover, it provides a framework for interpreting the findings. Chapter 4 provides details about the data as well as the methodological research design. Chapter 5 includes data analyses as well as the findings, interpreted mainly through previous literature. Chapter 6 provides a more complex and comprehensive discussion of the findings, interpreted through the theoretical framework presented in 
Chapter 3. Lastly, Chapter 7 concludes with suggestions for further research and considerations of the study's broader implications. 


\section{CHAPTER 2: Review of Literature and Definitions of Concepts}

\section{Overview}

The nature of globalization is a contested subject matter. Its definition varies qualitatively across actors, ideologies and disciplines. As Edwards points out, "Definitions of the phenomenon are as numerous as speculations about it" (Edwards 2006:587). Granted, globalization primarily emerged as an economic force and is generally perceived and experienced as such. But in our era of post-modern interconnectivity, where information, images, exchanges and interactions can occur intercontinentally within fractions of seconds, globalization has evolved into a force beyond economics. In order to provide a coherent context for the present research, the current chapter presents a comprehensive view of globalization, exploring its intricacies and multidimensionality.

The analysis is based on two overarching premises. The first is that the phenomenon of globalization is of a pervasive nature, casting its shadow on virtually every social, economic and political community on the globe (Falk 1999; Giddens 2000). The second is that globalization is extremely complex and multidimensional (Falk 1999; Giddens 2000). As Giddens suggests, globalization "is political, technological, cultural, as well as economic" (Giddens 2000:28). The complex nature of globalization is manifested in the fact that even though its forces are felt and experienced by virtually every individual around the globe, there is no consensus on its definition. It is therefore compelling to dissect the phenomenon and analyze its various dimensions in order to present it in a holistic manner. 
The present chapter begins with an historical analysis of globalization, focusing on its economic dimension and delineating its genesis. The emergence of globalization through the global colonial system and the driving forces behind colonialism are explored. Following this discussion, the exacerbation of and factors contributing to economic globalization in the $20^{\text {th }}$ century are examined. The impact of the Marshall Plan, the Bretton Woods System and the neo-liberal economic practices that have been particularly prevalent from the 1980s onward are assessed.

Furthermore, the impact of technology on the facilitation of globalization is explored. Specifically, the impact of technological advancements during the $19^{\text {th }}$ century's Industrial Revolution in Europe and the $20^{\text {th }}$ century's electronic revolution in the United States are considered. Next, an overview of the cultural implications of globalization and its political consequences is provided. Lastly, the determinant factors of opinion of globalization are assessed, providing an overview of what shapes peoples' attitudes toward the phenomenon.

\section{Economic Globalization}

In contemporary economics, neo-liberal globalization can be understood as the opening up of all economies which leads to the creation of a truly world market (Eurobarometer 2003). This involves the elimination of protectionist trade barriers - the official implementation of policies that restrict international trade, such as tariffs and quotas on foreign goods. Theoretically, this facilitates the free and efficient movement of goods and services between nation-states at unfettered prices. For example, following the U.S.-Canada Free Trade Agreement and the North American Free Trade Agreement 
(NAFTA), most tariffs affecting or limiting agricultural trade between the U.S., Canada and Mexico were removed (United States Department of Agriculture 2010).

While the above definition presents the subject matter as a rational, voluntary and systemic process, the fact of the matter is that the history of global economic exchange is rooted in centuries of conquest, power struggles and social dismay; namely, the global colonial system, which can be thought of as the genesis of globalization.

Colonization can be understood as "the subjugation by physical and psychological force of one culture by another - a colonizing power - through military conquest of territory and caricaturing the relation between the two cultures" (McMichael 2004:4). In practice, this entails the imposition of a system of social, political and economic control that challenges and distorts the existing societal structures of the subjugated parties.

The colonial period typically refers to the period of European colonial expansion between the $15^{\text {th }}$ and the $20^{\text {th }}$ century. This process was pioneered by the Kingdoms of Portugal and Spain through their exploration and subsequent colonization of the Coast of Africa, the Middle East, East Asia and the Americas, dating back to the $15^{\text {th }}$ century. In the $17^{\text {th }}$ century, England, France and the Netherlands followed suit. However, it was the $19^{\text {th }}$ and early $20^{\text {th }}$ century that saw the greatest rate of colonial expansion, particularly by The British Empire, France and later by Japan and the United States (Goff et al. 1998). During this time, The British Empire emerged as the largest empire in history, establishing colonies and settlements all around the globe. It hence came to be known as "the empire on which the sun never set". In order to fully grasp these historically 
significant phenomena and to assess the history of economic globalization comprehensively, one has to consider the driving forces behind European colonialism.

In considering the ideological propellants, nationalism was one of the biggest culprits (Goff et al. 1998). As will be discussed later, nationalism is an ideological outlook where the nation-state is put on the highest pedestal and rendered supreme and absolute. Nationalism emerged as particularly salient during the $19^{\text {th }}$ century in industrialized European nations (Goff et al. 1998). Against the backdrop of nationalism, nation-states sought to expand their empires as a means to increase their power, supply themselves with foreign goods and raw material and to display their superiority (Goff et al. 1998).

Colonial expansion can also be attributed to Europe's high held values of technological development and civilizational advancement (Goff et al. 1998). When the Europeans came into contact with indigenous cultures outside Europe, they often perceived them as primitive, uncivilized and uncultured. Using this skewed perception as moral grounds, Europeans conquered and subjugated indigenous people with the justification that they were helping them advance technologically and become civilized (Goff et al. 1998). As McMichael points out, "Development came to be known as the destiny of humankind" for the Europeans (McMichael 2004:8).

Religion also played a role in colonial expansion as Europeans sought to convert indigenous people to Christianity (Goff et al. 1998). Moreover, Europeans trying to avoid religious persecution at home settled colonies abroad, as is the case of the Puritan Christians setting up settlements and, subsequently, colonies in the Americas. 
Economic expansion and capitalism also played a very prominent role in colonial expansion (Goff et al. 1998; McMichael 2004). As will be discussed later, $19^{\text {th }}$ century Europe saw an unprecedented rate of technological expansion. This expansion was partly derivative of capitalist growth. In essence, capitalism necessitated and facilitated technological growth in the form of efficient industrial manufacturing, transportation and mass communications, the consequence of which was the expansion of capitalist economic exchange within Europe. As industries and manufacturing grew, so did European markets. However, industrial production increased at a disproportionately higher rate than local economies. This, in turn, necessitated the expansion of markets both within and beyond national borders. This was to be achieved through colonization.

The colonies functioned in two ways. First, they provided the raw materials that fueled European manufacturing. This resulted in a global system of labor division wherein colonies specialized in the extraction of raw materials and the production of primary goods that were then exported to European, industrialized countries and turned into finished products (McMichael 2004). These finished products were then exported back to the colonies for consumption. The colonies therefore also functioned as consumer markets (McMichael 2004). For example, under British rule, India exported cotton to England as raw material. The cotton was turned into cheap cloth in British factories and then exported back to India as a finished commodity (McMichael 2004). The culmination of the above events helped establish a global system of economic exchange which, with the help of $19^{\text {th }}$ century technological advancements, emerged as a pervasive global reality. But it took further economic developments in the $20^{\text {th }}$ century to elevate the 
phenomenon of globalization to a global existential milieu through the further expansion of the global economic system (Goff et al. 1998). In addition to the manufacturerconsumer cross-border relationships that were established in the $19^{\text {th }}$ century, the early $20^{\text {th }}$ century saw an increase in cross-border bank relations and financial investments (Goff et al. 1998). Economies around the world were interconnected like never before. The global economic collapse of the 1930s serves as proof. Instigated by the New York Stock Exchange, the collapse had the consequent effect of generating a world-wide economic depression (Goff et al. 1998). The latter half of the $20^{\text {th }}$ century saw an even greater intensification of global economic exchange and interconnectivity, mainly attributed to several key global initiatives led by the United States.

The first is the Marshall Plan, a bilateral development project mainly between the United States and Europe, which sought to reconstruct and stabilize national markets after the devastating events of the 1930s depression and the Second World War. This was to be achieved through a three way system of economic exchange. The United States would provide financial aid to other nations for development. Those nations would then finance the import of American technology and consumer goods. The Marshall Plan was an avenue through which the United States could promote its free market system and gain other nations' allegiance. It was therefore able to expand its economic and political influence and promote its global policy of containment, which attempted to prevent the expansion of communism. (McMichael 2004). The Marshall Plan saw great success as Europe and other non-European countries, like Japan, saw the restoration of their economies and the stabilization of trade (McMichael 2004). Moreover, the Marshall Plan 
contributed to the further expansion of the global economic system. Technological and economic progress came to be experienced not on a national, but on an international level and transnational investment, development and exchange were further amplified.

The second is the Bretton Woods system, a multilateral development project which sought to reconstruct the world economy in the 1940s by restoring trade, disbursing credit and liberalizing markets in areas that were devastated by the Second World War and colonialism (McMichael 2004). This was to be achieved through the creation of two main institutions. The first is the World Bank, whose function is to borrow money from international capital markets and invest it in the development of technology and infrastructure. The second is the International Monetary Fund (IMF), whose function is to disburse credit in order to stabilize national finances and currency exchanges in order to promote international trade (McMichael 2004). The Bretton Woods system had the effect of stimulating the world economy, expanding international trade and development and increasing economic exchange between the First and Third World nations (McMichael 2004). As an outcome, technological and economic development took international dimensions, creating transnational, multilateral economic, political and social linkages.

The post-World War II economic development projects had great success in restoring the world economy, the primary beneficiaries of which were Western nations. The 1950s and the 1960s were decades of continuous economic growth as national currencies and global trade stabilized. However, a different global reality emerged in the 1970 s - that of stunted economic growth, rising unemployment and high inflation (Cohen 
and Centeno 2006). The economic uncertainty of the 1970s helped empower the emerging neo-liberal economic school of thought that would dominate the next three decades (Cohen and Centeno 2006). The main premises of economic neo-liberalism are that:

- The role of the state must be reduced because national governments are wasteful and inefficient (Cohen and Centeno 2006). Government owned sectors of the economy should be privatized to ensure competition, motivation and innovation. This is expected to create wealth that will eventually trickle down to everyone in the country.

- Conservative monetary and fiscal policies must be implemented. Government spending should be reduced to allow the economy to function freely. State programs such as welfare and subsidies should be eliminated (Cohen and Centeno 2006).

- National markets should be deregulated to encourage direct foreign investment, especially from multinational companies (Cohen and Centeno 2006). This is expected to lead to global efficiency and specialization in production, and ensures the transnational flow of capital, workforce, raw material and products at lower costs.

- Protectionist trade barriers such as tariffs and quotas should be eliminated (Cohen and Centeno 2006). This facilitates the free and efficient movement of goods and services between nation-states at unfettered prices.

In the 1980s, the neo-liberal school of thought emerged as the most dominant (Cohen and Centeno 2006). The relentless advocacy for global economic liberalism by then U.S. president Ronald Regan and U.K. Prime Minister Margaret Thatcher helped elevate neo-liberalism from an ideology to a global reality (Cohen and Centeno 2006). 
Moreover, the International Monetary Fund and the World Bank began implementing policies that were very much in accord with the neo-liberal school of thought (Cohen and Centeno 2006). More specifically, loans made by the World Bank and the IMF to Third World countries were tied to structural adjustment policies. These structural adjustment policies necessitated the liberalization of markets. Essentially, aid was only given to countries whose economic policies met the IMF's and the World Bank's standards of economic liberalism. This resulted in the implementation of neo-liberal economic policies, such as decreased assistance to the poor and reduction of subsidies to domestic businesses and farmers. Moreover, during the 1970s and 1980s, the World Bank and IMF along with private and national banks, lent immense amounts of money to Third World countries (McMichael 2004). These loans were used by elites to develop national infrastructure, strengthen militaries and enrich their networks with lucrative contracts (McMichael 2004). However, during the 1980s, the U.S. Federal Reserve, in an attempt to curtail the falling value of the dollar, aggressively reduced its money supply (McMichael 2004), the effect of which was the contraction of credit, higher interest rates and the issuance of shorter-term loans (McMichael 2004). This resulted in the Third World debt crisis, when poorer countries, given the new economic and loan conditions, were unable to pay back the immense amounts of money they borrowed.

The combined effects of the Third World debt crisis and the concurrent implementation of neo-liberal economic policies had devastating economic consequences (Stiglitz 2002; McMichael 2004; Ganguly-Scrase and Vogl 2008). Until this day, the policies of the World Bank and the IMF are criticized and blamed for causing more 
poverty in Third World countries and for working in favor of richer Western nations and companies at the expense of poorer countries. Suffice it to say, however, that international economic liberalism has been a contributing factor to increased poverty and greater economic inequality in both Western and Third World nations (Alderson and Nielsen 2002; McMichael 2004). For this reason, it is prudent to distinguish the phenomenon of economic globalization from its accompanying vice of global income disparity.

Theoretically, there is nothing inherent in the phenomenon of globalization that presupposes increased poverty and economic inequality. In fact, the global economic system has both merits, an example being the global economic boom of the 1960s, and vices, an example being the global economic collapse of the 1930s. The adverse consequences of globalization can be attributed to many factors, ranging from the West's historic control of world markets to the proliferation of neo-liberal economic practices. These factors have often been conflated with the notion of global economic interconnectivity. While it is clear that these factors might exist within the global economic system, they are not necessarily its equivalent. The global economic system can be considered a structural reality remnant of the post-colonial economic system - a reality that nation-states cannot ignore. Despite the negative effects of economic globalization, nation-states are unable to subsist outside the global economic system. It is for this reason that a recent Pew Global Attitudes survey found broad support for economic globalization throughout the world. Most notably, the survey found that subSaharan Africa, the world's poorest region, was strongly in favor of international trade, 
with over $80 \%$ of the respondents stating that international trade was having a positive impact on their country (Kohut and Wike 2008). Therefore neo-liberalism is perhaps more accurately assessed not as the equivalent of globalization but rather, as one of its potentially malevolent counterparts. In essence, neo-liberal advocates take advantage of the reality of globalization in order to spread an economic ideology that often results in pervasive global economic disparity.

Neo-liberalism's greatest expansion followed the collapse of the Soviet Union, which had the consequent effect of empowering the West and globally reifying free market economics. The 1990s and the early $21^{\text {st }}$ century saw an ever increasing global trend toward global economic liberalism as more countries were integrated into the global economic system and as more countries implemented neo-liberal economic policies. This is reflected in the ratification of a series of international free trade agreements during that time, such as the General Agreement on Trades and Tariffs (finalized 1994), The North American Free Trade Agreement (enacted 1994), The Association of South East Asian Nations (signed 1992), The African Economic Community (enacted 1994), The Greater Arab Free Trade Area (adopted 1997), The Central European Free Trade Agreement (enacted 1994), The Dominican Republic-Central American Free Trade Agreement (enacted 2006) and the Pacific Island Countries Trade Agreement (enacted 2003) (The African Economic Community 2010; The Association of South East Asian Nations 2010; World Trade Organization 2010).

The culmination of these economic developments further contributed to the global integration of financial markets and to global economic interdependence (Castells 1996). 
The self-sustained national economy ceased to be a reality in the $21^{\text {st }}$ century. The current study is structured against this backdrop of economic interdependence as a global milieu. More specifically, the current study is premised on the fact that global economic interconnectivity and interdependence have inadvertently, but surely, compromised national sovereignty (Habermas 1998a; Habermas 1998b; Falk 1999; Giddens 2000; Sassen 2006). The nation-state can no longer function adequately outside a globalized framework and, as a consequence, is subjected to external forces, pressures, dependencies and exposed to the volatility of the global economic system (Habermas 1998a; Habermas 1998b; Falk 1999; Giddens 2000; Sassen 2006). These ideas are further explored in Chapter 3.

\section{Technology and Globalization}

Technological advancement can be considered the propellant of globalization. The unique characteristics of modern and post-modern technology, which have been constructed around their interface with the positive sciences, have furnished the infrastructure on which the globalizing structure and phenomena have been built. There are two historical facets of technological advancement and development that have propelled the phenomenon of globalization.

The first are the technological advancements of modernity in the $19^{\text {th }}$ and early $20^{\text {th }}$ century in Europe during the Industrial Revolution. This period saw the transformation of agricultural and manual labor production to mechanically-based manufacturing (Ellul 1964; Goff et al. 1998). Several key inventions and scientific advancements contributed to this technological progress: 
- The increased and efficient use of refined coal which, for the first time, allowed for the production of immense amounts of energy (Toffler 1980);

- The invention and refinement of steam power and the steam engine (Toffler 1980; Goff et al. 1998);

- More sophisticated utilization of water wheels and powered machinery (Toffler 1980);

- The invention of electricity and electric light (Toffler 1980; Goff et al. 1998);

- The invention of telecommunications such as the telephone and the telegraph (Goff et al. 1998).

These advancements facilitated the mechanization of production industries (Toffler 1980). Mechanized production was pioneered by the textile industry and was eventually also adopted by other sectors of production. Moreover, these advancements in technology allowed for rapid trade expansion both within Europe and between Europe and its colonies through the introduction of steam boats, improved roads, railways and canals (Toffler 1980). As trade expanded globally, so did technological advancement.

Therefore, global technological development can be thought of as a derivative of the dialectical relationship between technology and capitalism (Ellul 1964). In essence, the already established system of global economic exchange necessitated technological advancement in the form of more efficient ways of production, communication and transportation. As technology expanded and advanced globally, so did global economic exchange (Toffler 1980). This created a global system of economic interdependences contingent on and facilitated by modern technology (Toffler 1980). 
The second phase of technological innovation, which further propelled the phenomenon of globalization, occurred in the mid-twentieth century. The 1960s and 1970s saw the advent of a new wave of technological development centered on information technologies. This movement was pioneered primarily by the United States. It was driven by an emerging culture that emphasized and valued technological innovation, and by the challenges put forth by an increasingly growing and demanding global system of economic exchange, communication, management and production. During this time, the technological advancements that had the greatest impact on the proliferation of technology, communication and global interconnectivity were:

- The invention of microelectronics such as transistors, integrated circuits and microprocessors, enabling communication with and between machines (Castells 1996);

- The creation of general-purpose, commercial and personal computers, enabling the spread of information technology (Castells 1996);

- The standardization of computers, such as the creation of operating systems, enabling the interconnectivity of information technology and communication between parties (Castells 1996);

- The creation of network systems wherein multiple client computers are integrated around a more powerful and specialized server computer, enabling the capability of instantaneous interactive data sharing (Castells 1996);

- Advances in telecommunications, such as in optoelectronics, digital packet transmission, satellite broadcasting, microwaves, digital telephony technology and so 
forth, enabling faster and more diverse avenues for communication and dissemination of information (Castells 1996);

- The invention of the internet, elevating interconnectivity, communication and information dissemination to an unprecedented level.

These technological advancements resulted in an existential paradigm shift, primarily in the West and eventually throughout the rest of the globe. Electronic technology has redefined economics, societies, communities, politics and cultures. As Castells notes, "A technological revolution, centered on information technologies, is reshaping, at accelerated pace, the material basis of society" (Castells 1996:1). Moreover, post-modern technology has allowed for an unprecedented level of interconnectivity and ease of communication and information sharing that has elevated the phenomenon of globalization to an existential milieu. As McMichael suggests, in regards to economics, "Advances in telecommunication technologies enable firms, headquartered in global cities such as New York, London, or Tokyo, to coordinate production tasks distributed across sites in several countries" (McMichael 2008:83). The spread of information technology has not only accelerated the rate by which the world is globalized, but has also changed the way globalization is experienced.

Technology has allowed for a more intimate, dialectic experience between the individual and the forces of globalization. As Castells suggests, "networks are growing exponentially, creating new forms and channels of communication, shaping life and being shaped by life at the same time" (Castells 1996:2). Recent events in Iran serve as testimony to this statement during the country's globally publicized anti-government 
protests in the aftermath of disputed presidential elections. The Iranian government, in an attempt to save its global reputation and maintain its stronghold over its citizens, had successfully blocked foreign media from entering the country and had virtually barred any media outlets from broadcasting the events overseas. However, it was unable to block its citizens' utilization of online social networks, such as Twitter, to disseminate vast amounts of information and media about the protests (Batty 2009). These events illustrate not only how interconnected the world has become due to technology, but also how dependent it has become on technology. This interplay of global interconnectivity and technological dependency has generated a new form of consciousness - one that is defined by globalized phenomena via the medium of technology. This global consciousness carries cultural implications that should be considered.

\section{Cultural Implications}

Cultural globalization can be thought of as the intensification of global interactions and relations among people (Giddens 2000; Lagos 2003). These interactions can occur on many levels. For instance, they can occur on a personal basis. An example would be business professionals of different nationalities meeting for common purposes and interests. Another example would be that of an immigrant coming into contact and interacting with local nationals. These sorts of interactions facilitate the inter-cultural flow of language, ideas, reasoning, methods and culture. An immigrant forming relations and friendships with local nationals might, for example, share and pass on traditional food recipes. 
Interactions in a globalized world, however, extend far beyond personal interaction. Interactions can take place via various other channels of communication such as economic exchange, technology, media, politics, pop culture and so forth. In all cases, these interactions impact and affect culture. Consider the September $11^{\text {th }}$ attacks on the World Trade Center and its implementation and impact on U.S. and world culture. This event was partly facilitated by the global interconnectivity of communication, economic exchange and technology, which enabled the terrorists to fund, coordinate and implement their plans of attack. In the aftermath of the attacks, the event was instantaneously transmitted and delivered to virtually every part of the U.S. and the rest of the globe. The effects on U.S. and global culture were broad and long-lasting. In the U.S., the attacks resulted in widespread national grief and terror, coupled with an exaggerated sense of national pride and militancy. The result was the consequent invasion of Afghanistan and Iraq and a reconfigured international political strategy characterized by pre-emptive strike and military dominance. In considering the impact of the September $11^{\text {th }}$ attacks on world culture, one can say with conviction that the terrorist attacks induced a global feeling of sympathy toward the U.S. (NZ Herald 2001). This enabled the U.S. to put together an international military coalition and to invade Afghanistan.

What becomes increasingly clear is that the forces of globalization are so pervasive and strong that they have the capacity to transform the way individuals experience themselves, their communities, their cultures and ultimately the rest of the world. As Edwards suggests, interactions in the framework of globalization change "how actors perceive themselves and their interests" (Edwards 2006:588). In other words, there 
is a shift in people's consciousness. In this sense, cultural globalization is of a more qualitative, nebulous and implicit nature. In assessing Western cultural hegemony, about which much has been said and written, consider the example of a youngster growing up in a traditional society but who also has access to the global media, either through television or the internet. In the process of this individual's development it is more likely that he or she will espouse both the values of his or her immediate, traditional community and those of the West, which tend to dominate the global media. As Castells suggests, “[...]a new communication system, increasingly speaking a universal, digital language is both integrating globally the production and distribution of words, sounds, and images of our culture and customizing them to the tastes of identities and moods of individuals" (Castells 1996:2).

In this sense, one can see how the forces of globalization have also generated a global culture; better yet, something that resembles culture. This cultural wave has been, for the most part, led by the West and spread through global capitalism, technology and the media (Berger 2000). This emerging form of culture is of a post-modern quality deconstructed, non-referential, abstract and of multiple and conflicting dimensions. This is a radical departure from culture conceived in the conventional sense which entails art, norms, customs, and behaviors rooted in years of history, social consensus and interaction. This new form of global culture can be conceived as the continuous establishment of ephemeral values, trends, lifestyles, norms, art and behaviors.

Consider the example of hip-hop music and culture. This form of art was at some point uniquely localized and specific to African Americans and was generated through a 
unique collective experience - that of slavery, segregation and racialized poverty in the U.S. Nonetheless, hip-hop, as an art form, culture and behavior has spread throughout the globe and has been adopted by individuals whose experience is far removed from that of African Americans. To use a comparison, if we were to conceive of culture in the conventional, traditional sense, this would be the equivalent of a Belgian adopting the mannerisms and expressions of an Italian! Another poignant example of how values are adopted on a global scale is the recent surge in environmental consciousness (Falk 1999; Giddens 2000), partly attributed to the fact that environmental change is an issue of global effects and implications. Environmental activists and scientists have cooperated on a global scale and have had a huge impact on mainstream environmental politics (Falk 1999). This was made possible through the utilization of global media, communication and culture. Thus, it becomes increasingly clear that cultural globalization is contingent on technology, the media and economic exchange, all of which can be thought of as the facilitators and vehicles of interaction.

\section{Political Consequences}

A system of global economic, cultural and technological interconnectivity gives rise to a global political sphere. Governments are intrinsically tied to the economic and technological infrastructure of their countries in the forms of regulation, management, oversight, execution and so forth. Globalization extends the economic and technological infrastructure beyond the borders of nation-states via economic liberalization and technological interconnectivity and, as a result, so does the reach of the government. The 
outcome is the emergence of a global political sphere and transnational political action and interaction (Falk 1999).

This occurs in several ways. The simplest example is the establishment of diplomatic relations between countries where issues such as economic exchange, tourism and travel and financial assistance can be jointly addressed. Another example is the establishment of joint technological projects between countries, such as the creation of cross-border gas or oil pipelines. For instance, Ukraine and Russia collaboratively administer a cross-border gas line which transfers natural gas from Russia through Ukraine to Europe.

Increasingly though, the global political sphere necessitates political action between multiple political actors because the globalized economic, social, political and technological system has become so complex and volatile that it cannot be managed unilaterally (Habermas 1998a; Falk 1999; Giddens 2000). The perfect example of this is the European Union, a system of political, economic and social exchange, in which issues, policies and laws are proposed, addressed and ratified on a collective level.

Globalization poses two basic challenges for nation-states. The first is how to manage the effects of globalization. The nature of the phenomenon is such that the occurrence of distant events can have significant, and in some cases, severe effects on the nation-state (Falk 1999; Giddens 2000). Iceland's recent financial turmoil serves as proof to this assertion. In 2008, it essentially went bankrupt as a consequence of the U.S. housing and credit crisis (Associated Press 2008). Therefore, part of the role of the national government is to effectively manage its political, economic and technological 
constitution in relation to the rest of the world in order to ensure the survival and progress of the nation-state. The second challenge of the nation-state is to preserve its local distinctiveness. Globalization has the capacity to transform the way individual actors perceive themselves, their societies, their communities and ultimately the rest of the world. As a result, nation-states feel threatened and overwhelmed by globalization because it has the potential to be accompanied by external influence. This sense of threat becomes more salient as individuals and communities actually experience the erosion of their local distinctiveness. This fear translates itself into the political realm both in benevolent and malevolent ways. In either case, the government is given the task of preserving local distinctiveness and managing the impact of globalization.

One can see how the issue of national sovereignty is central to both challenges. As will be explored later, the pervasive forces of globalization have the tendency to compromise national sovereignty. The manner in which nation-states react to this reality is central to the current study.

What proceeds in the following sections is an exploration of the intricate complexities of the nation, the state and their convergence. There are three key conceptual elements that are useful in understanding their connection: national institutions, national consciousness and national sovereignty.

\section{National Institutions, National Consciousness and National Sovereignty}

National institutions are the public institutions of a nation-state that facilitate and assist in the implementation of its structural social, political, economic, legal and bureaucratic processes. The systemic convergences of these institutions generate the state 
apparatus - the legitimate representative and manifestation of the nation. The nation-state system as an organizational apparatus has come to define Europe (and ultimately the rest of the globe) ever since the advent of modernity in the $19^{\text {th }}$ century (Wallerstein 1999; Sassen 2006). As mentioned earlier, Europe experienced exponential technological progress and economic growth during this time and, as a consequence, rapid urban expansionism. In essence, growth in industrial production necessitated increases in labor force and consumer markets. As Ellul points out, "a crowd of human beings began to gather about the machine. A great number of individuals were necessary to service it; an equally great number were required to collect about it to consume its products[...] With this development came the hitherto unknown phenomenon of the big city" (Ellul 1964:113).

What followed was the emergence of mass culture, characterized by mass industries, large urban centers, mass communications and mass transportations. These newly generated mass societal structures could not be managed by traditional social institutions, such as those of the family and the immediate community. Ellul suggests that individuals did not spontaneously adapt to this new form of mass society (Ellul 1964). Instead, this necessitated the creation of a mass and highly integrated organizational system - the territorially defined modern state apparatus. As such, the state came to be experienced as a vehicle that ensured the well-being of the general populace (Sassen 2006). But what enabled the state apparatus' emergence, actualized through the collective agency of the people it represented, is a concurrent emergence of a collective national consciousness (Anderson 1983; Deutsch 1996). 
Anderson traces the roots of this emergence to the Protestant Reformation and the rise of print-capitalism, both of which had a considerable effect in reshaping the traditional values and social structures of Europe (Anderson 1983). The Protestant Reformation had the effect of eroding the Catholic Church's absolute standing which, in turn, compromised the societal continuity that had been sustained by Christendom for centuries through religion. Much of the Protestant Reformation's impact can be attributed to the availability of print, which allowed for the mass production and circulation of vernacular biblical translations. Prior to the invention of the printing press, the bible had been written in Latin and was only made accessible through religious institutions. Its content and interpretation was therefore only available through the religious leadership. The publication of the bible in vernacular languages eroded the power of the Catholic Church, which lost its vantage as the exclusive mediator between the collective consciousness and the religious text (Anderson 1983).

Moreover, print-capitalism had the effect of reducing the number of languages in Europe, as well as their respective dialects, through homogenization. Prior to the printing press, people speaking the same language often found it difficult if not impossible to communicate due to variances in dialect. With the advent of print, however, came the creation of standardized syntax and grammar. Coupled with the fact that books could be produced and distributed at an astounding rate, people from different regions found that they could now communicate through print. As Anderson points out, "These fellowreaders, to whom they were connected through print, formed, in their secular, particular, 
visible invisibility, the embryo of the nationally imagined community." (Anderson 1983:44).

However, it was not until the $19^{\text {th }}$ century that national consciousness emerged in its definitive form. Prior to the industrial revolution and the advent of mass society, social reality was personal, intimate and, most importantly, manageable by traditional institutions. Individuals were closer and more intimate to the instruments of social organization, those being the family, church and immediate community. The collective consciousness was fostered within this intimate framework and, conventionally, affirmed through the practice of religious rituals (Durkheim 1915). Through religious worship, the community was essentially reifying its morals, values, beliefs and norms and, essentially, reinforcing the collective consciousness (Durkheim 1915).

However, the advent of mass society saw the erosion of the family and the immediate community as social organizational instruments. This necessitated new and larger mechanisms of social organization that were structurally relevant to the industrially induced massification of society. The result was the advent of the modern state apparatus as a system of social integration. However, this created a social experience wherein individuals were far removed from the social organizational instruments, manifested in a faceless and abstract state apparatus. Moreover, as a consequence of mass society, individuals became part of a social order that extended far beyond their immediate social environments.

This necessitated an alternative collective consciousness - one which encompassed a vast and integrated mass society. The result was the emergence of a 
collective ethnic national consciousness. As Smith points out, "National identity fuses the socio-cultural properties of a community with its political order and its territorial habitat. Through myths of autonomy, fraternity and authenticity, nationalism creates the only credible popular basis for large-scale social and political units." (Smith 1993:9). Similar to its traditional counterpart of religion, this new form of collective consciousness is reified through collective self-worship via rituals, myths, symbolic imagery and social institutionalization, now centered on the nation-state (Anderson 1983; Smith 1993).

What follows is an abstract and highly perceptual collective mental process wherein the state-apparatus is experientially fused with a heightened collective national consciousness to formulate the notion and the experience of the nation-state. This is a process in which the collective consciousness experientially converges with the structural realities put forth by the state apparatus, functioning as an all-encompassing parent figure and guarantor of social security and functionality. This instigates feelings of collective security, solidarity and agency, and the collective self is reaffirmed via the state apparatus and a mass social order.

The culmination of these experiences and circumstances gave rise to a phenomenon that has since come to define the human experience: nationalism. Nationalism is a world view that presupposes the superiority of the nation-state (Anastasiou 2008b). Anastasiou defines it as "the unprecedented moral absolutization of the nation, its freedom, its interest, its community, its identity, and its power, in combination with the derivative presumption that its supreme moral status furnishes thereby 'the right' to employ all means, including adversarial and lethal means, in the 
nation's defense, sustenance, advancement, expanding powers, and alleged 'destined' historical realization" (Anastasiou 2008b:32).

Paradoxically, the absolutization of the nation's values and power and its right to exercise force (nationalists conceive this as the legitimate use of violence) is practiced not only against people of other nations but also against its own people when the agents of nationalism deem it necessary. Throughout the past two hundred years, numberless horrors and cruelties have been committed in the name of the nation-state (Smith 1993; Goff et al. 1998). Most, if not all, wars in recent history have been fought in the name of the nation. Ironically, even the cruelest acts committed by states against their own people were done in the name of the nation.

By implication, nationality entails an effective way of ensuring behavioral control over the nation's members (Deutsch 1996). Any deviation from the prescribed standards is confronted with sanctions. The nation-state represents a uniquely exaggerated social power structure which has the power to legitimately intervene in every aspect of peoples' lives - the family, the community, the education system, the private sector, the public sector, politics and so forth. The nation-state exists much like an invisible force, dictating thought, prescribing action and motivating the masses. While social relations have always existed through power structures, there is something qualitatively and quantitatively different about how power is instated and imposed in a nation-state system (Deutsch 1996).

This reality is rooted in the fact that rigid and definitive structures of power that can be effectively implemented in the entire spectrum of society are necessitated by 
modernism and mass society by virtue of their complexity and size. What results, is the granting of exaggerated and absolute power to the state apparatus along with the ability to exercise its power through sophisticated techniques and technological means. Nationalism rationalizes this vulgar display of power by infusing historic, social and, at times, religious moralisms and mythical narratives into the collective conscience, thusly conflating and equating moral action with state efficacy. This process is then institutionalized through "informal social arrangements, pressure of group opinion, and the prestige of national symbols" (Deutsch 1996:28). Power in this sense can be exercised more strongly and more effectively "through formal social or political organizations, through the administration of educational or economic institutions, or through the machinery of government" (Deutsch 1996:28). In other words, nationalism has come to define the collective and individual consciousness by defining social force relations, either explicitly or implicitly.

The nation-state, however, should not be understood as a social entity abstracted from the agency of individuals. It is the will and support of the people that enable the efficacy of the nation-state in sustaining the social normative order. However, the executive, legislative and ideological structures of the nation-state are ultimately prescribed by a small group of powerful nationals, which includes high level politicians, economic elites, the intelligentsia and the military. In fact, the emergence of nation-states was, in addition to what was delineated earlier in this section, driven by the economic and power interests of this elite group of nationals. 
Compared to the average citizen, these power elites have a disproportionately greater capacity to utilize the state apparatus due to their status and social, political and economic advantages. Often, they do so in their own interests and at the expense of the larger population. Government corruption is the most prevalent example. War driven by economic consideration is the most perverse. Their deeds are masked, more than anything else, by the nationalistic and ideological value systems and narrative that they themselves prescribe to the broader populace. This diverts citizens' attention from the elites' transgressions to ideological abstractions (such patriotism, national loyalty and national interest) that have extremely powerful symbolic significance in the context of nationalism. Nationalism can thus be conceived as an extremely powerful tool in social engineering that has the capacity to be used for both benevolent and malevolent purposes, depending on the nation's leadership. One issue that has long been used to motivate and distract the masses is national sovereignty.

The emergence of the nation-state is intrinsically tied to a collective rigid conceptualization of national sovereignty (Sassen 2006). National sovereignty can be understood as the perceived supreme and absolute authority of the nation-state, embodied by its independence, to manage, regulate and define all its affairs and aspects which are either tangibly contained within its visible borders or that are intrinsically or extrinsically related to its invisible mental reach (Krasner 2001; Rankin 2001). In practice, this entails state intervention and imposed control in potentially every aspect of social life including the economy, the national border, education, family and even social interaction, to serve the nation-state's interest. Ellul agrees with this assertion by pointing out that "The 
technological revolution meant the emergence of a state that was truly conscious of itself and was autonomous in relation to anything that did not serve its interest" (Ellul 1964:43).

What is clear is that this absolute conception of national sovereignty is a direct derivative of nationalism. More specifically, rigid conceptions of national sovereignty can be linked to the absolutization of the nation-state, coupled with the supposition that the nation-state has the inherent right and capacity to define all its associations without being subjected to or controlled by any external forces.

The current study is centered on the subject matter of national sovereignty. Specifically, what will be explored is the interplay between national sovereignty, as a derivative of nationalism, and economic globalization. Indeed, the nation-state system, along with nationalism and the derivative assumption of national sovereignty, has come to define modernity and post-modernity as we know it. The only system of social organization that has taken exception to and has challenged this system is the EU.

\section{The European Union}

The European Union is a political, economic and social union comprised of 27 member states (Europa 2009). Since its establishment, the EU has striven for cooperation and solidarity to prevent poverty and international conflict and to promote unity and fraternity among its member states (Anastasiou 2008a; Europa 2009). These principles are premised on the rule of law, security and justice, peace and stability, diversity and economic and social solidarity (Europa 2009). From an economic standpoint, the EU is a single market trading bloc that guarantees free trade between its member states through 
the elimination of protectionist barriers, such as tariffs and quotas (McCormick 2005; Wood and Yesilada 2006). For example, French automakers can sell their cars to Austria without being subject to any form of tariffs, as though they were Austrian automakers. From a social standpoint, the EU guarantees freedom of mobility (travel and migration), work and education between its member states (McCormick 2005; Wood and Yesilada 2006). For example, within the EU, a Cypriot national can work in Germany with virtually no restrictions, as though he or she were actually German.

To better understand the EU, one must consider Europe's modern history and, specifically, its long-lasting political, economic and social turmoil and continuous warfare. Furthermore, it is important to comprehend the pervasive historical significance of nationalism in Europe, particularly in light of its World War II evolution. Modern-day Europe can be characterized by peace, stability and solidarity but this was not always the case. In fact, in modern history, Europe had been continuously entrenched in warfare, up until the end of the Second World War.

The treacherous and catastrophic events of WWII had a profound impact on Europe and had the effect of steering it into a new direction. It is, therefore, no surprise that the official EU website explicitly states that "The European Union is set up with the aim of ending the frequent and bloody wars between neighbours, which culminated in the Second World War" (Europa 2009). However, what we now know as the EU is not merely a result of the realization that peace and solidarity should take precedence over war and conflict. Rather, the EU is also the outcome of decades of highly reflective deliberations and initiatives that had the capacity of institutionalizing peace and 
cooperation. It primarily emerged as an economic project whose aim was to promote unity among its member states through economic integration and through the elimination of hunger and poverty. In this sense, the genesis of the EU can be considered to have been heavily incentivized by economic considerations. This holds true for both the political and economic leaders who propelled the project but also for the general populace that granted its support. These collective decisions were heavily influenced by The Great Depression of the 1930s, which had the effect of generating extremely adverse social and political conditions in Europe. But the EU has since moved beyond simply economic integration to social and political integration. What follows is a brief outline of the history and evolution of the EU.

In 1950, the European Coal and Steel Community was founded by Belgium, France, Germany, Italy, Luxembourg and the Netherlands, placing coal and steel production under joint authority. This was the first step toward European economic and political unity as an attempt to avert future conflict and to secure peace (Europa 2009).

The 1960s saw a surge in economic growth and expansion as members of the European Coal and Steel community opened up their economies and eliminated trade barriers. In 1968 the Common Agricultural Policy was established, granting joint control over food production to its members to eliminate waste and hunger (Europa 2009).

On January $1^{\text {st }} 1973$, Denmark, Ireland and the United Kingdom joined the European common market. The EU's regional policy transferred large amounts of money and capital to poorer areas for job creation and infrastructure development. During this time, Europe saw its last right-wing dictatorships come to an end with the overthrow of 
the Salazar regime in Portugal in 1974 and the death of General Franco of Spain in 1975 (Europa 2009).

In 1981, Greece became the $10^{\text {th }}$ member to join the EU and in 1986, Spain and Portugal followed suit. In 1987 the Single European Act was signed, enabling the freeflow of trade between EU member states' borders and creating the European 'Single Market'. On November $9^{\text {th }} 1989$, there was major political upheaval when the Berlin Wall was pulled down and in October of 1990 Germany was united for the first time in 28 years (Europa 2009).

The collapse of the Iron Curtain brought forth new challenges as well as opportunities for the EU. In an attempt to reconcile with their neighbors, the EU and Eastern Europe agreed to multilateral arms reduction. The EU began investing in Eastern Europe in an attempt to elevate their standard of living so that they can later have the opportunity to accede into the EU (Europa 2009).

In 1992, The Maastricht Treaty was ratified, extending the powers of the EU beyond the economic realm. In 1993 the 'Single Market' was completed, further opening up borders with the free movement of goods, services, people and money. Moreover, in 1995, Austria, Finland and Sweden acceded into the EU. In 1999 The Treaty of Amsterdam was ratified and, in an attempt to strengthen citizenship, individual rights and democracy, increased the power of the European Parliament (Europa 2009).

In the period following the new millennium, the euro, a single transnational European currency, became the currency for most EU countries. The political and social divisions between Eastern and Western Europe ceased to be a reality when in 2004 eight 
central and eastern European countries joined the EU: The Czech Republic, Estonia, Latvia, Lithuania, Hungary, Poland, Slovenia and Slovakia. Additionally, the island of Cyprus and Malta also became EU members (Europa 2009). The year 2007 concluded the accession process with the inclusion of Bulgaria and Romania (Europa 2009).

What is important to consider is that the EU is the only supranational organization in the world. Its structure is unlike that of international organizations, such as the United Nations. International organizations such as these are inter-governmental in their structure and presuppose the "voluntary cooperation and coordination between or among its members, but has neither autonomous powers nor the authority to impose its rulings on its members" (McCormick 2005:4). The EU is a supranational organization whose structure of governance also entails transnational authority and powers configured in a system of shared national sovereignty. In essence, when a country joins the EU, it gives up a portion of its national sovereignty due to the fact that EU law, on various issues, supersedes national law, as is the case with environmental, economic and human rights laws. For example, Turkey's ambitions to join the EU were hampered when it failed to adhere to the EU's freedom of movement laws when it blocked its air and sea ports to Cyprus (Euronews 2006). Moreover, the EU system is set up so that there is shared control and a balance of power, not just between constituent nations, but between the union itself, its member states and its citizens. This process is elaborated and implemented by its three main institutions.

The European Commission is the executive branch of the EU, representing the common good of the EU as whole. It is often referred to as the "conscience of the EU". 
The European Commission has three main functions: to suggest and propose new legislation and policies; to ensure the implementation of new legislation after it has been ratified and to promote the interest of the EU integration process (McCormick 2005). As McCormick points out, "It is the most supranational of the EU institutions, and has not only encouraged member states to harmonize their laws, regulations and standards in the interests of removing barriers to trade, but has been the source of some of the most important policy initiations since the 1960s, including the single market programme and the development of the euro" (McCormick 2005:82). However, it is important to note that even though the European Commission has the power to suggest and introduce legislation and policy, it does not have the power to ratify it. That power rests with the Council of Ministers and the European Parliament.

The Council of Ministers is the intergovernmental legislative branch of the EU (McCormick 2005). It is the body that negotiates and ratifies bills that have been introduced by the European Commission. The Council of Ministers, unlike the European Commission, represents the individual interests of the EU's 27 member states (McCormick 2005). As McCormick points out, "The Council of Ministers is the major decision making branch of the EU, the primary champion of national interests, and arguably the most powerful of the EU institutions" (McCormick 2005:89). The legislative process takes place via inter-governmental negotiation and compromise. This process is elaborated by state ministers and diplomats in nine distinct councils, determined by the topic under consideration (McCormick 2005). For example, finance ministers meet to 
discuss economic issues while foreign ministers meet to discuss issues regarding external policy.

The European Parliament is the supranational legislative branch of the EU, representing the citizens of the EU (McCormick 2005). It consists of political parties that have multinational representation. For example, the European Parliament's Green Party can have representatives from Belgium, Cyprus, Romania, France and Estonia. These representatives, unlike those of the European Commission and the Council of Ministers, are directly elected by EU citizens. In this sense, the European Parliament can be considered the most democratic of all EU institutions. Over the years, the European Parliament has successfully managed to accumulate more powers. As it stands, the European Parliament has legislative and budgetary authorities and oversight power over the Union's institutions (Europa 2009). In essence, EU legislation is based on cooperative decisions by the EU Parliament and the Council of Ministers.

It is clear that the EU is a unique economic and socio-political system in many respects. Perhaps, though, what is most unique about the EU is the fact that it is a system consciously constructed in response to globalization. Central to the present study is EU citizens' unique experience of globalization through the EU. As previously mentioned, the EU is an intergovernmental and supranational system of shared sovereignty. This alters the experience of globalization due to the fact that, in participating in a system of shared national sovereignty, the experience of the nation-state takes on a supranational dimension. The EU also functions as a buffer against the vices of globalization by increasing the collective power and efficacy of its member states. Moreover, it has 
redefined the meaning of citizenship in Europe by granting supranational democratic rights to its citizens, thereby expanding the experience of the citizen beyond borders. The relationship between EU citizens, the EU and globalization will be explored in greater detail in Chapter 3. What proceeds is an assessment and exploration of the determinant factors of opinion of globalization through previous literature.

\section{Determinant Factors of Opinion of Globalization}

The phenomenon of globalization has evoked considerable academic interest in recent years. In the last decade, there has been an increasing trend particularly in observing peoples' opinions of, and attitudes toward, globalization. What follows is a literature review examining the determinant factors of opinion of globalization. From a theoretical standpoint, the following section elicits insight and understanding of how people perceive and form judgments about globalization. Methodologically, it generates an array of control variables that are used in the analysis to counter spuriousness (expanded on in Chapter 4).

Additionally, due to the study's focus on the EU, literature examining opinion of EU integration is also assessed. The EU can be considered a construct that mediates national attachment and globalization. As has been mentioned and is expanded on in Chapter 3, EU citizens experience the phenomenon of globalization through the EU, a supranational, intergovernmental institutional response to the phenomenon of globalization. For this reason, it is prudent to examine the determinant factors of EU integration opinion because, as mediating factors, they might influence EU citizens' 
opinion of globalization. This is done to elicit greater theoretical understanding of what shapes EU citizens' opinion of globalization.

Several studies indicate that higher levels of education are generally positively correlated with support for trade integration (Rankin 2001; Scheve and Slaughter 2001; Mayda and Rodrik 2005). This relationship is generally stronger in wealthier countries and either weakened or reversed in poorer countries (Mayda and Rodrik 2005). Another demographic determinant is average wage or income, which is generally positively correlated with support for trade integration (Scheve and Slaughter 2001). For example, Mayda and Rodrik find that individuals whose income is higher than the national average tend to be in favor of trade integration while those at the bottom end of income distribution tend to have a protectionist outlook (Mayda and Rodrik 2005). Skill level is also positively correlated with greater support for trade integration (Scheve and Slaughter 2001). However, as is the case with education, this relationship holds true for wealthy nations and is either weakened or reversed in poorer nations (O'Rourke and Sinnott 2001; Mayda and Rodrik 2005).

There are several possible explanations for the above findings. Trade integration generally benefits wealthier nations and wealthier individuals and, in certain instances, generates adverse social and economic conditions for less economically developed countries and poorer individuals (Alderson and Nielsen 2002; Stiglitz 2002; GangulyScrase and Vogl 2008; Meschi and Vivarelli 2009). Wealthier countries and individuals with higher levels of education, skill level and income, all of which are positively correlated, are in a better position to benefit from trade integration and are thus in favor 
of it. However, this relationship is reversed in poorer countries. Poorer countries are more vulnerable to the effects of free trade. Hence, individuals of higher income, education and skill level who reside in poorer countries tend to be against trade integration because of the fact that they are conscious of this vulnerability.

Age is another predictor of opinion of globalization. A Eurobarometer survey on opinion of globalization finds that younger respondents tend to be in favor of globalization (Eurobarometer 2003). Mayda and Rodrik and Edwards find similar trends in regards to age, in that older individuals tend to have more protectionist attitudes and are more skeptical of globalization (Mayda and Rodrik 2005; Edwards 2006). However, other studies suggest that age is neither a predictor of trade liberalization nor of supranational ties (Rankin 2001).

Findings linking age with opinion of globalization are typically attributed to a recent emergence of supranational conceptions of identity and the development of a postnational global consciousness, typically more prevalent among youths (Jung 2008). More education in foreign languages and greater rates of travel to foreign countries are a contributing factor (Jamieson 2005). Moreover, the internet, global popular culture icons, exposure to global news media and the rise of international consumer brands have had the effect of connecting youths around the globe (Jung 2008). This has had the effect of deteriorating traditional rigid conceptions of national identity and paving the way for supranationalism and embrace of globalization.

There is also a gender gap when it comes to opinion of globalization (O'Rourke and Sinnott 2001). Steve and Slaughter and Mayda and Rodrik, for example, find that 
women tend to be more protectionist than men (Steve and Slaughter 2001; Mayda and Rodrik 2005). There are several possible explanations for this. Globalization has generated economic conditions disproportionately favoring men (Boserup 2007). For example, Sassen observes that while large scale service industries like finance are run by men on the executive level, they are supported and sustained by low paid, manual workers, many of whom are women (Sassen 1996). Globalization and neo-liberalism have also generated vulnerable social and economical conditions for women such as forced migration, reduction in health services, sex trafficking and increased impoverishment (Sassen 2000; Ganguly-Scrase and Vogl 2008).

Occupational sector has also shown to predict opinions of trade integration. Rankin finds that blue collar workers are more likely to be against trade integration and NAFTA (Rankin 2001). Mayda and Rodrik find that individuals in both the import and export sector of the economy are against free trade but that those in the export sector have less of a tendency to be against trade integration (Mayda and Rodrik 2005). Steve and Slaugher, however, find little evidence for the claim that occupational sector predicts opinion of trade integration (Steve and Slaugher 2001).

Trade union membership has also been found to predict trade integration. There is a tendency for trade union member to be against globalization (Mayda and Rodrik 2005). For example, Rankin finds that trade union members are both against trade integration and NAFTA (Rankin 2001). Locality is also proven to be a predictor of opinion of globalization. Mayda and Rodrik, for example, find that individuals living in rural areas are more likely to be of a protectionist outlook (Mayda and Rodrik 2005). 
Other studies have shown that values predict opinion of globalization. In a crossnational survey, Edwards finds that individuals deeply rooted in their traditional way of life tend to have an unfavorable view of globalization because they feel threatened by its invasive effects (Edwards 2006). Edwards also finds that individuals who have negative views of consumerism are more likely to be against globalization (Edwards 2006). There have been conflicting findings on whether partisanship plays a role in predicting opinion of globalization. Mayda and Rodrik, after controlling for various variables, find that political party affiliation has no effect on trade integration preferences (Mayda and Rodrik 2005). On the other hand, Steve and Slaughter find that in the U.S., Democrats (left) systematically express more protectionist opinions compared to Republicans (right) (Steve and Slaughter 2001). Rankin finds a similar trend wherein Republicans (right) tend to be in favor of free trade compared to Democrats (left) (Rankin 2001). Interestingly, when assessing political ideology as opposed to partisanship, different results arise. For example, Rankin and Steve and Slaughter find that those who label themselves as conservative have a more protectionist outlook (Rankin 2001; Steve and Slaughter 2001).

On first glance, findings regarding partisanship and political ideology appear quite contradictory and inconclusive. This is due to the fact that globalization can be opposed from both the political left and the right but for different reasons. The political right opposes globalization in defense of national sovereignty, while the political left opposes it on its perceived neo-liberal character. What is clear, however, is that both 
partisanship and political ideology play a marginal role in predicting opinion of globalization but could, nonetheless, be useful control variables.

Economic conditions are also determinants of opinion of economic integration. Edwards finds that individuals who feel that the economy will worsen within the next year are more likely to have a negative opinion of cultural, technological and economic globalization (Edwards 2006). Research further suggests that individuals' assessment of the economy as a whole might be a stronger predictor of opinion of globalization than one's personal economic assessment. For example, Rankin finds that individuals' personal economic evaluation did not predict opinion of trade integration (Rankin 2001).

More pertinent to the current study, there have been attempts to explore the relationship between national attachment and opinion of globalization. These studies show that individuals with higher levels of national attachment are more likely to be in favor of trade protectionism and against globalization. As Rankin, suggests, "National identity has the added significance of cutting across multiple cleavages in which patterns of trade liberalization evoke symbolic predispositions" (Rankin 2001:370). Rankin finds that individuals who tend to express rigid loyalty to the nation and tend to have restrictive conceptions of culture and sovereignty are opposed to trade integration and NAFTA (Rankin 2001). O'Rourke and Sinnott's findings are similar. They find that nationalism, patriotism and chauvinism are strongly associated with protectionist attitudes (O'Rourke and Sinnott 2001). Mayda and Rodrik also find that nationalism and rigid conceptions of patriotism are strongly associated with trade protectionism (Mayda and Rodrik 2005). 
These findings are very much in accord with the theoretical framework that is presented in Chapter 3. Globalization has had the effect of compromising the sovereignty of nation-states (Habermas 1998a; Habermas 1998b; Falk 1999; Giddens 2000; Sassen 2006). This, in turn, generates nationalistic reactions wherein the nation-state, its structures and its symbols are posited in opposition to globalization or any form of international integration and ultimately rejected (Falk 1999; Rankin 2001; De Vries and Edwards 2009). As Rankin asserts, "Sovereign conceptions indicate how much value citizens attach to restricting external influence on domestic autonomy, including territorial space, cultural expression, economic and political control" (Rankin 2001: 361). When exploring the determinants of opinion of EU integration, several factors are at play. Hooghe and Marks, for example, find that collective and personal economic expectations are both positively correlated with EU integration favorability (Hooghe and Marks 2005). In their words, "The presumption is that citizens evaluate the economic consequences of European integration for themselves and for the groups of which they are part, and that such consequences motivate their attitudes" (Hooghe and Marks 2005:420). Gabel and Whitten's findings are similar but suggest that assessments of the economy as a whole, as opposed to one's personal economic expectations, are greater predictors of individuals' opinion of EU integration (Gabel and Whitten 1997). The salience of economic conditions in predicting people's opinion in regards to EU integration is not surprising. As is explored in Chapter 3, the EU is a project initiated on economic incentives and considerations. It attempts to integrate nation-states economically by providing a supranational social and political platform for integration. 
Nonetheless, perceptively, what is most salient about the EU is its economic character and its success in granting economic benefits in the context of managed and steered integration.

In exploring the interplay between skill level and income, Gabel finds that, as manual workers' income increases, their support for EU integration decreases (Gabel 1998). The opposite holds true for professional workers (Gabel 1998). In assessing how values affect opinion of EU integration, De Vries and Edwards find that European integration is opposed by both the political right in defense of national sovereignty, and the political left based on the perception that the EU possesses a neo-liberal agenda (De Vries and Edwards 2009). In regards to nationalism, Hooghe and Marks find that individuals who hold exclusive conceptions of national identity oppose EU integration (Hooghe and Marks 2005). Moreover, these individuals are more likely to oppose EU integration when their country's political elites are divided over the issue.

Assessing peoples' opinions of globalization is very important, particularly due to the fact that this phenomenon is not just a mental reality, but an existential socioeconomic milieu; and when a phenomenon affects every individual's consciousness, it deserves our attention. For the purposes of this study, what will be explored is the interplay between opinion of globalization and national attachment, specifically within the EU, conceptualized as a conscious response to the phenomenon of globalization.

It is important to comprehend the pervasive historical significance of nationalism in Europe, particularly in light of its post-WWII evolution. Whereas modern day Europe can be characterized by peace, stability and, generally, solidarity between its member 
states, this was not always the case. As previously mentioned, historically, up until the mid-1940s, Europe had always been entrenched in warfare. The epitome of this is, obviously, the two world wars: World War I, which resulted in the death of 20 million people, and World War II, which resulted in the unprecedented death of 60 million people. Europe's bloody history, especially during the $20^{\text {th }}$ century, can be, among other factors, attributed to its peoples' embrace of nationalism and the myth of ethnic superiority, as well as citizens' placement of absolute trust in their respective states, national leaders and national institutions (Dogan 1994; Goff et al. 1998).

In this context, one can observe how globalization presents opportunities, as well as challenges for nation-states (Falk 1999; Giddens 2000; Sassen 2006). Globalization has facilitated conditions of economic and political turmoil between nation-states, an example being the world economic collapse of the 1930s which paved the way and the conditions for WWII (Goff et al. 1998). However, globalization has also facilitated conditions of international cooperation as is the case with the UN, NAFTA, OPEC, and supranational cooperation, as is the case with the EU.

While the literature has addressed the subject matter of globalization quite thoroughly, particularly in assessing its effects and outcomes, a question that has only been marginally addressed is under what conditions can globalization function in a way which elicits supranational cooperation (as opposed to competition) and conditions of post-national economic, social and political solidarity. Since the EU can be considered, partly, a conscious, institutional and systemic response to globalization, it is prudent to examine it. The proposed study is unique in that it examines EU citizens' opinions of 
globalization within the only economic and sociopolitical system wherein national sovereignty is compromised but also shared. In conducting the study one can address more provocative questions:

- How does living in a system of shared sovereignty impact individuals' view of globalization?

- Is national attachment posited in opposition to globalization in a system wherein national sovereignty is shared?

- How is the interplay between national attachment and globalization configured in an economic socio-political system consciously constructed to manage the phenomenon of globalization?

Europe presents a great opportunity when addressing these broader questions particularly because it is the birthplace of nationalism and because its history has been defined by the phenomenon. What proceeds is a theoretical exploration of the interplay between globalization, nationalism and the EU, which serves as the framework for the present study. 


\section{CHAPTER 3: Theoretical Framework}

\section{Globalization and National Sovereignty}

The present study examines whether trust placed in national institutions correlates with EU citizens' opinion of globalization. A salient theme in the literature is that the forces of globalization, as a post-modern phenomenon, are simultaneously in unity and tension with the more traditional structures of the nation-state (Habermas 1998a; Habermas 1998b; Falk 1999; Giddens 2000; Sassen 2006). The former stems from the fact that the phenomenon of globalization presupposes, at the very least, an economic consensus between nation-states on a global scale. The latter stems from the fact that the forces of globalization compromise the sovereignty of nation-states. The nation-state's dependency on the global economic system is a structural necessity that facilitates its survival. In other words, in order for the nation-state to survive in an era of post-border technological and economic interdependency and interconnectivity, it must succumb to the forces of globalization (Habermas 1998).

Globalization has had the effect of weakening the sovereignty of nation-states as national governments are increasingly unable to protect themselves from the social, economic and political side-effects of the global economy (Sassen 2006). More specifically, the vulnerability of nation-states can be attributed to the fact that the global economic system has weakened the state-apparatus. In an attempt to harmonize their country's economy with the neo-liberal norms of the global economic system, nationstates have tended to under-utilize the state apparatus in regards to social and economic sustainability. As Habermas points out, the state apparatus' "reduction has resulted from 
a supply-wide economic policy that seeks to deregulate markets, reduce subsidies and improve investment conditions" (Habermas 1998a:1).

As mentioned in Chapter 2, neo-liberalism, in recent years, has emerged as the dominant global economic ideology and seeks to deregulate markets by limiting government intervention in the economy. Neo-liberal advocates have been highly successful in their endeavors to open up and deregulate economies around the globe. These consist of politicians, economic elites and corporations seeking economic benefit. Their attempts to liberalize markets have been highly successful due to their advantageous social and economic status and power that enable them to utilize the nation-state in their favor. Their success in doing so has paved the way for the emergence of a highly interconnected, global economic system which nation-states have been compelled to accommodate and on which nation-state are, in turn, highly reliant.

As a result, governments either willingly (as is generally the case with developed countries) or through economic coercion, adhered to neo-liberal economic practices even though their implementation may yield only marginal benefits and in many cases even cause further economic problems. The alternative option of implementing economic protectionist policies is no longer viable, as it inevitably forces nation-states' economies into a degenerative state, unable to provide to its citizens the diverse array of necessary products and services that are available through the global economic system (Habermas 1998a). Case in point: in the midst of increased poverty and social disorder, caused in part by neo-liberal economic practices, Third World countries are generally welcoming to multinational corporations, due to the fact that they offer employment to their citizens. A 
study by Kohut and Wike, found that Ghanaians, Senegalese, Nigerians and other individuals from Africa, the world's poorest continent, are especially welcoming to multinational corporations (Kohut and Wike 2008). What is significant about these findings is that global economic liberalism generates conditions under which nationstates and individuals have no choice but to participate in the global economic system.

Economic isolationism, in an era of rapidly expanding economic interconnectedness, characterized by an already existing post-colonial system of international specialization and division of labor, limits opportunity for economic expansion and fosters economic stagnation. Global economic outreach, on the other hand, allows access to a wider array of economic systems and markets and the opportunity for international exchange and investment. As McMichael points out, "economic nationalism came to be viewed as limiting development because it obstructed the transnational mobility of goods, money, and firms in the service of efficient allocation of global resources" (McMichael 2004:152). This becomes increasingly clear when assessing nation-states that have been thoroughly marginalized from the international community. For example, North Korea, a state excluded from the global economic system, faces tremendous challenges in sustaining its economy.

The power of the global economic system is thusly derived from its capacity to essentially coerce nation-states to open up their economies. The nation-state is therefore compelled to compromise its sovereignty in a two-fold manner. It is forced to participate in an economic system which extends beyond its borders and, in doing so, loses a measure of control of its economic system. 
Globalization has also had the effect of compromising the sovereignty of the nation-state in various other fashions. It has, for one, redefined the symbolic and experiential meaning of citizenship (Falk 1999; Sassen 2006). Traditionally, the notion of citizenship was intrinsically tied to the nation-state. This relationship was re-enforced in the institutionalization of the citizen-national through education, warfare and cultural institutions (Sassen 2006). As a consequence, the citizen pledged exclusive allegiance to the nation-state as the basis for his or her nationality. In return, the nation-state, much like an exaggerated parent figure, became the guarantor of survival, order, development, security and social stability. As Sassen points out, the "state came to be seen as a key to ensuring the well-being of significant portions of both the working class and the bourgeoisie" (Sassen 2006:284). In this sense, the symbolic significance of the citizen was conflated with that of the nation-state.

However, national governments are more and more straying away from their role as providers and local development managers, as they shift their focus on managing their countries' role in the international economic system (McMichael 2004). Practices such as outsourcing, reduced welfare and policies which allow for the loss of unionized jobs, greatly contribute to the waning meaning of citizenship as states provide less and less to their citizens and individuals are increasingly pressured to rely on themselves for their well-being and social security.

But the fact of the matter is that a compromised state-apparatus undermines the very conditions it was designed to provide - guaranteeing economic freedom on the one hand and social, political security and freedom on the other, essentially harmonizing free 
market capitalism with liberal democracy. As Habermas points out "Social costs are rising to levels that might exceed the integration capacity of liberal societies. Growing poverty and social insecurity have emerged as a corollary of growing income disparities, and social disintegration has followed" (Habermas 1998a:1). This holds true, in varying degrees, in both the wealthier Western and the poorer Third World nations. In this sense, globalization has redefined the state-apparatus, and consequently the nation-state, both structurally and symbolically as it is more and more experienced as a relative entity in the midst of a multitude of global forces.

The structural realities of globalization come in direct conflict with the nationalistic world view - a perspective which cannot accept the notion that the superior nation-state and especially its sovereignty can be subject to external forces. National sovereignty can be defined as the perceived supreme and absolute authority of the nationstate, embodied by its independence, to manage, regulate and define all its affairs and aspects which are either tangibly contained within its visible borders or that are intrinsically or extrinsically related to its invisible mental reach (Krasner 2001; Rankin 2001).

This rigid conception of national sovereignty is historically associated with nationalism's absolutization of the nation-state. Nationalism can be defined as "the unprecedented moral absolutization of the nation, its freedom, its interest, its community, its identity, and its power, in combination with the derivative presumption that its supreme moral status furnishes thereby 'the right' to employ all means, including adversarial and lethal means, in the nation's defense, sustenance, advancement, 
expanding powers, and alleged 'destined' historical realization”' (Anastasiou 2008b:32).

Thus, the derivative belief is that the nation-state has the inherent power and right to define all its associations. It, therefore, cannot be subjected to or controlled by any external forces.

This particular outlook is further reinforced by the fact that the collective consciousness of modern, post-industrial societies has been, to a large extent, shaped by the interaction and confluence of an imagined national community with an all encompassing state-apparatus (Anderson 1983). The experience of the individual and the collective are intrinsically tied to the nation-state. A compromised nation-state is therefore experienced and perceived as a compromised self and a compromised social community. It is for this reason that individuals who have rigid nationalistic conceptions of national identity and express rigid emotional connections to the nation-state are particularly skeptical and resentful of any sort of external forces that might have an impact on the nation-state but which have not been defined and determined by it (O'Rourke and Sinnott 2001; Rankin 2001; Hooghe and Mark 2005; Mayda and Rodrik 2005).

These external forces are particularly salient on the economic level as nationstates are increasingly constrained by systemic global economic interdependencies which, in turn, compromise their political, cultural, social and economic volition and agency (Habermas 1998a). It is through this framework that the current study looks at the relationship between trust placed in national institutions and opinion of globalization within the EU. 


\section{National Institutions}

National institutions are selected as a key element for analysis because they are the public institutions of a nation-state that facilitate and assist in the implementation of its structural social, political, economic, legal and bureaucratic processes. The systemic convergences of these institutions generate the state-apparatus, the legitimate representative and manifestation of the nation.

What is clearly evident in the literature is that the forces of globalization operate, at least in part, in opposition to the nation-state. This holds true both when assessing theoretical academic work and large scale public opinion polls (Habermas 1998a; Habermas 1998b; Falk 1999; Giddens 2000; O’Rourke and Sinnott 2001; Rankin 2001; Hooghe and Mark 2005; Mayda and Rodrik 2005; Sassen 2006). What transpires in Chapter 2, in assessing determinants of opinion of globalization, is that individuals who tend to be nationalistic or have stronger emotional ties to the nation-state tend to be against globalization and trade integration.

The current study builds on the literature by assessing levels of trust in nationalinstitutions in relation to opinion of globalization. This particular focus can be considered a natural evolution of the literature as the focus is shifted away from nationalism as a value or outlook. Instead, national institutions, being the legitimate representation and manifestation of the nation on the structural social, political, economic, legal and bureaucratic level, are considered. In this sense, the current study is bridging the world of values, i.e. nationalism and national attachment, to the structural and functional realities, i.e. national institutions. One expects that there exists an integrative dialectical relationship between the two, in that individuals who have higher levels of trust in their 
national institutions have a more nationalistic world view that rejects any external forces that compromise the sovereignty or the symbolic conception of the nation-state and, therefore, have a negative opinion of globalization. The present study explores whether this relationship exists within the EU.

\section{The European Union}

The EU is a political, economic and social union comprised of 27 member states (Europa 2009). Since its establishment, the EU has striven for cooperation and solidarity to prevent poverty and inter-national conflict and to promote unity and fraternity among its member states (Habermas 2002; Anastasiou 2008a; Europa 2009). These principles are premised on the rule of law, security and justice, peace and stability, diversity and economic and social solidarity (Europa 2009). From an economic standpoint, the EU is a single market trading bloc which guarantees free trade between its member states through the elimination of protectionist barriers, such as tariffs and quotas (McCormick 2005; Wood and Yesilada 2006). From a social standpoint, the EU guarantees free mobility (travel and migration) and free movement of human labor between its member states (McCormick 2005; Wood and Yesilada 2006).

The structure of the EU is unique in that the economic and sociopolitical processes of its member states also take place beyond the boundaries of the nation-state through regional democratic institutions that member states jointly manage. This poses a challenge as well as an opportunity for globalization research where the relationship of the self-contained nation-state and the invasive forces of globalization are conventionally assessed in opposition to one another. The EU, among other things, is a unique response 59 
to the phenomenon of globalization (Habermas 1998b; Leonard 2006). It attempts to manage the pervasive effects of globalization in a highly structured and regulated social, political and economic system. This process is elaborated in the re-configuration of democracy through, but also beyond, the nation-state. As Lagos points out, "in the formation of the predecessors to the European Union, we see a desire to diminish the solitude of individual countries in Europe in order to increase their collective strength" (Lagos 2003:336). More specifically, this process is premised on the principle of shared sovereignty (Giddens 2000; Anastasiou 2008a). Practically, this entails the implementation of various structural social, political, economic, legal and bureaucratic processes beyond the national state apparatus. These processes take place both on an intergovernmental and supranational level through transnational democratic decisionmaking. As Hooghe and Marks point out,

"The European union meshes national and European governments in a system of multilevel governance that pools sovereignty over important aspect of citizens' lives. To the extent that European integration makes it more difficult for national governments to pursue distinctly national preferences, it undermines national self-determination and blurs boundaries between distinct national communities" (Hooghe and Marks 2005:423).

This convergence of highly integrated and inter-country administrative, commercial and regulatory processes, function to mitigate possible threats of globalization and nationalism (Lagos 2003; Anastasiou 2008a). Lagos calls this process "steered democratic globalization" (Lagos 2003:336). 
It becomes clear that EU citizens are considerably unique and different from citizens of conventional systems of socio-economic governance, where sovereignty and power is principally and solely lodged in the nation-state. In the interest of the study, it is prudent to assess how EU citizens might be unique in the way they experience the phenomenon of globalization. Citizens living in a sociopolitical structure delineated by the boundaries of the nation-state, experience globalization as an external force. EU citizens, on the other hand, in light of the fact that they are part of a system of shared sovereignty, might have a bifurcated experience of globalization, where it is seen as an internal force which is integral to their system of social organization - the EU - but also as an external force to their respective nation-states.

Furthermore, EU citizens experience the phenomenon of globalization, not solely through their nation-state, but also through the EU. When countries join the EU, they experience an intensification of the phenomenon of globalization. This is due not only to the fact that they are required to adopt non-protectionist and open-border policies toward countries within the EU, but also to the fact that they are required to adopt similar policies toward the broader international community (McCormick 2005). From a cultural standpoint, this results in emigration to and immigration from other EU countries, such as Poland and The Czech Republic. From an economic standpoint, it leads to a huge influx of foreign investment money and also the opportunity for investment in other EU countries and the broader international community.

Moreover, the EU grants its citizens higher levels of agency. This is manifested in the EU's focus on citizens' rights and democracy wherein supranational rights and 
freedoms are granted to its citizens, such as the right to travel and work freely in any EU country (Giddens 2000; McCormick 2005). This might have a considerable effect on the way individuals experience globalization given that they may feel empowered in the face of its invasive potential. For example, in the $\mathrm{EU}$, a single citizen has the right to take any government or private business within the EU to court on the basis of EU law violation.

EU citizens are also unique in the way they experience national attachment. Europe has seen a trend in recent years in decreasing levels of nationalism, often attributed to the EU's unique structural configuration based on shared sovereignty. As Hooghe and Marks point out, the EU "provokes a sharp sense of identity loss among defenders of the nation (national attachment) and among anti-cosmopolitans (multiculturalism)" (Hooghe and Marks 2005:423). Empirical evidence confirms this.

In a study of European nationalism, Mattei Dogan finds that nationalism levels in Europe have, in general, decreased (Dogan 1994). For example, in 1981, fewer Germans, French, Italians, Belgians and Dutch were "very proud" of their nationality, compared to 1970. On the other hand, Greece, Spain and Ireland showed sustained levels of national pride between 1981 and 1991which Dogan attributes to recent turbulent national events that were still salient in the collective memory (Dogan 1994).

There is also a trend in decreasing levels of confidence in the national army (Dogan 1994). For example, between 1981 and 1991, the average number of individuals in the European Community who had "great deal of confidence in their army" decreased from $20 \%$ to $13 \%$. Moreover, the majority of many European countries, such as the Netherlands, Denmark and Belgium, do not display confidence in their armies. When 
Germans were polled in 1990, they ranked the army last as a national investment priority and preferred expenditure in health, housing and schools. Interestingly, a 1990 poll showed that two thirds of the French were in favor of a common European defense. As Dogan suggests, "one of the traditional components of nationalism - the capacity of military defense of individual countries - seems to be fading" (Dogan 1994:40). The exceptions are Britain and Finland, both of which display high levels of confidence in their army.

As confidence in the army wanes, so does the will to fight for one's country (Dogan 1994). In 1981, only 43\% of those polled in nine European countries were willing to fight for their country while $40 \%$ were not. For example, only $35 \%$ of Germans, $31 \%$ of Italians and $27 \%$ Belgians were willing to fight for their country. It becomes clear, that the socio-political climate of present-day Europe stands in sharp contrast to that prior to World War II.

Trustworthiness between Western European nations is also on the rise (Dogan 1994). The absolute majority of all Europeans polled in 1980 expressed trust in nine out of thirteen European countries considered. Italy, Greece, Spain and Portugal were the only ones not perceived as trustworthy by the majority of other Europeans. However, between 1976 and 1990 levels of mutual trust increased for almost all countries, including trust toward Greece, Portugal, Spain and Italy. Britain was the only exception, whose level of trust toward other European countries did not improve. Similarly, there was a decrease in trust toward the British by other Europeans. Most notably, Dogan finds that the majority of both the Germans and the French expressed high levels of trust in 
each other (Dogan 1994). The French perceived the Germans as being the most trustworthy nation and vice versa. This stands in sharp contrast to the past, when the French and the Germans, in vehemently hating one another, attempted to reduce each other to rubble in the context of two world wars. As Dogan asserts, "World wars belong to history, European unification represents the future.” (Dogan 1994:45).

As levels of mutual trust in European countries increase so does the collective European consciousness (Dogan 1994). Polls show that there is a rise in positive attitudes toward European unification in all countries within the EU. Supranationalism is on the rise as nationalistic trends decrease in a framework of economic, social, cultural and political solidarity (Dogan 1994). Moreover, there is the realization that economic nationalism is a thing of the past. As Dogan suggests, "This interdependency engenders a supranational market, detrimental to old-fashioned economic isolationism and protectionism" (Dogan 1994:49). As markets and borders open up, people, ideas and goods are circulated and exchanged freely. Additionally, it is interesting to note that more Europeans have crossed borders within Europe in the decades since World War II than in the previous eight centuries.

In light of the above, the EU can be conceived as a transnational economic sociopolitical entity, consciously designed to manage the phenomenon of globalization and its potential volatile nature. This occurs in an interactive and dialectic fashion, wherein, in the context of globalization, economic stability and benefit are bolstered and reinforced strategically by the promotion of supranationalism, transnational democracy and shared national sovereignty. On the individual level, what drives peoples' support of the EU is 
economic benefit. The salience of economics within the context of the EU is reflected in the fact that, when EU citizens are asked to consider what the EU means to them personally, choosing among a list of items, the second most popular response (chosen by $50 \%$ of the respondents) is the Euro (Eurobarometer 2004). The prominence of economics within the EU context is also observed historically. The EU has always emphasized economic sustainability as a deterrent of social unrest. For example, the EU's Common Agricultural Policy, which aims to ensure reasonable food prices for its citizens and fair incomes for farmers, comprises $45 \%$ of the EU budget (Europa 2009).

What is important to note, in regards to such programs and policies, is that within the EU, economic liberalism is enacted so long as its potential economic and, as a consequence, social and political vices are curtailed. For example, the EU's Structural and Cohesion funds, which comprise $35 \%$ of its budget, aim to reduce economic inequalities between member states. These funds are mainly contributed by the EU's richest member states and are then diverted to countries and areas of low economic standing to promote development and job creation. In practice, this reduces income gaps between countries and regions, the result of which is greater common economic benefit.

But what enables the success of the EU's economic policies is the fact that they are also reinforced by political integration which has the effect of further empowering the bloc. Transnational cooperation on the political level is essential to this process. But cooperation within the EU also means giving up national powers and compromising national sovereignty. This is observed on multiple levels. It is, for one, observed in the willingness of member states to give up a portion of their economic national sovereignty, 
in contributing to a common fund aimed for development in economically disadvantaged areas. It is also observed in areas where EU law supersedes national law. In the case of the environment, EU member states are forced to adhere to the EU's environmental standards, due to the fact that common environmental standards ensure fairer business practices between member states.

These processes of economic and political integration are further reinforced by cultural and social integration, which, even though is implicit in the context of salient economics and politics, is nonetheless paramount to integration. Present day EU can be characterized by immense waves of transnational migration and travel as well as transnational work and educational opportunities. On the social level, this not only contributes to the intensification of interactions between people of different ethnicities, but it also contributes to the creation of an integrated European cultural identity. It is by no surprise that when EU citizens are asked to consider what the EU means to them personally, the most popular response (chosen by $50.2 \%$ of the respondents) is freedom to work, study and become educated in the EU (Eurobarometer 2004).

Implicitly, this rise of European consciousness reinforces the economic and political structures on which the EU is built. It is for this reason that in his speech of May $28^{\text {th }} 2001$, then French prime-minister Lionel Jospin called for greater supranational social integration, based on a European way of life. In his words,

"Until very recently, the efforts of the Union focused on the creation of monetary and economic union[...] Today, we need a wider perspective going beyond this, 
otherwise Europe will become simply just another market which will disintegrate under the effects of globalization. After all, Europe is much more than a market. It symbolizes a social model whose growth has historical dimensions" (European Navigator 2010)

But perhaps, one of the greatest contributions of EU social integration, as facilitated by its economic and political success, is curtailing nationalism. What proceeds is a comprehensive analysis of the contributing factors to decreasing levels of nationalism within the EU.

\section{Reasons for Decreasing Levels of Nationalism}

Europe's decreasing levels of nationalism, among other things, can be attributed to the EU's system of shared national sovereignty. European nation-states are generally small or mid-sized countries that have proven to have greater political, cultural, scientific and economic potential in unity (Dogan 1994). As European integration moves forward, so does each country's capacity and potential for progress. Economic progress, in particular, has shown to be negatively correlated with levels of nationalism (Dogan 1994). The EU has enabled greater economic growth for its member states by creating a large transnational economic market and by sustaining peace. Creating a peaceful political environment not only allows for free travel, trade and cooperation but also allows for decreased military spending and allocation of national budgets toward social and economic sustainability. Furthermore, the EU, by its emphasis on the rule of law, human rights and democracy, has allowed for the emergence of a new European civic culture wherein basic values, perspectives and social experiences are congruent between 
nations. As Dogan suggests, "the differences within nations are greater than differences between countries" (Dogan 1994:59).

This socio-cultural climate is accompanied by an emergence of a supranational consciousness - that of the European citizen - that complements and integrates national consciousness in a manner that is unprecedented. This can be considered a derivative of the EU's harmonization process, in which laws, economic, political and social practices are standardized between countries (Dogan 1994). While this transfer of power from the national to the supranational level is rarely pronounced, it has shown to be consistently effective in sustaining supranational integration and in nourishing supranational identities (Dogan 1994). Dogan, in agreement with the theoretical framework put forth in the present paper, further suggests that "The sovereignty of the nation-state is slowly but progressively reduced by a kind of loose confederal sovereignty, called vaguely ‘Community”' (Dogan 1994:60).

To some, the EU might appear as a fascinating, intriguing and unique phenomenon. But there are also those, particularly in the public political sphere and the mainstream media, who consistently fail to recognize the EU's contribution to its European countries - the sustenance of peace and socio-economic stability in the aftermath of two world wars. For example, in a 2006 Newsweek article, journalist Fareed Zakaria, prophesized the decline of Europe. The article describes the author's perspective of how the EU, through its socio-political and economic functions and structures, is debilitating itself. 
Specifically, Zakaria takes aim at the EU's economic regulations, what he perceives as its inability to reform and, most notably, its dwindling military spending. In his words, "Its dwindling defense [the EU's] spending weakens its ability to be a military partner of the U.S., or to project military power abroad even for peacekeeping purposes" (Zakaria 2006:45).

Pat Buchanan, American conservative political commentator, syndicate columnist and broadcaster and presidential hopeful, also took aim at the EU recently. His basic premise is that the EU is an eroding system due to its incapacity to elicit love and loyalty from its constituents because, as he puts it, "The EU is a thing of paper, an intellectual construct. Unlike a nation, it has no heart and no soul" (Merino 2008:46). Most notable, is Buchanan's analysis of Europe's recent peaceful history. As he suggests,

"it was not the EU that [kept] Europe secure and at peace. America kept the Red Army from the Elbe and the Rhine [rivers bordering Germany]. America saved Western Europe from the fate of the Hungarians in 1956, the Czechs in 1968 and the Poles in 1981. America pulled the British and French chestnuts out of the Balkan fires of the 1990s" (Merino 2008:43)

He then continues, by stating that "German-French amity is a product of statesmanship, but also of the defeat of France in 1940 and the reduction of Germany to rubble by the American, British and Soviet armies in 1944-1945" (Merino 2008:44). The claim that Europe is a peaceful continent because of the U.S.'s military might and that the 
relationship of France and Germany is one of unity because they reduced each other to rubble is academically unsound, to say the least.

These perceptions typically stem from uninformed views of the EU and its history. The fact of the matter is that present-day Europe can only make sense when assessed against its historical backdrop of nationalism, particularly prevalent in the first half of the $20^{\text {th }}$ century, the socio-political outcome of which were two world wars, 60 million casualties and the destruction of a whole continent. It is through these realities that the EU has emerged, coupled with the explicit realization that war was not the answer in dealing with the pervasive effects of a globalized political, social and economic reality.

Zakaria and Buchanan both fail to comprehend the fact that present day Europe is a united and peaceful continent, partly because it has shifted its attention away from defense spending and display of military might, actualized through mutual, intergovernmental arms reduction agreements. Rather, supranational cooperation is in order, configured in a system of social, political and economic integration and through shared national sovereignty, which has had the consequent effect of mitigating nationalism and the negative effects of globalization. Zakaria fails to grasp this too, when he criticizes Europe's leaders for "backtracking on their proposals and instead mouthing pious rhetoric about the need to 'manage' globalization" (Zakaria 2006:45).

Moreover, a frequent mistake that (particularly U.S.) public figures make, is to talk about the EU as if it is a country, in the likes of a federation, such as the U.S.. Granted it would be easy to criticize the EU if it actually were a country, due to its lack of 
power and executive mechanisms to fully implement laws and regulations - powers that national governments hold comprehensively. However, in realizing that the EU is actually a group of individual countries that come together in a system of shared political, social, economic and national sovereignty, one understands both its exceptionality and its success in overcoming the traditional nationalistic barriers that have kept nations and people apart, divided and, at times, in conflict for the past two centuries. Nonetheless, challenges still remain.

\section{The End of Nationalism?}

While Europe has seen a decline in nationalism since the end of the Second World War and the establishment of the EU, nationalist tendencies still remain and are, at times, considerably pronounced. The truth is that despite an emergent European culture and a blossoming European consciousness, national identities are predominantly the most salient (Hooghe and Marks 2005).

Globalization, as an external force, has had the effect of rejuvenating nationalist tendencies in the European public. As stated earlier, this can be attributed mainly to the fact that globalization compromises the sovereignty of nation-states and has redefined the symbolic and experiential meaning of citizenship. In the wake of exacerbated economic liberalism, citizens find themselves confronted with the reality that their country has to succumb to external forces in order to survive in the context of the global economic system. Moreover, the changes brought forth by globalization are rapid and exponential, creating a sense of uncertainty and uneasiness in the European public. For this reason, the 
issue of globalization has been most prevalent in the framework of EU politics (Feron 2004).

But often, in the context of constant change and compromised national sovereignty, citizen nationals revert to nationalist ideals in an attempt to compensate for the uncertainties of globalization. As Rankin points out, "national identity, however, may be evoked and even reinforced by political debate concerning the relationship between trade liberalization, national sovereignty and cultural integrity” (Rankin 2001:353). Citizen nationals, therefore, experience the EU in a bifurcated manner. On the one hand, they experience the EU as an effective steering force in the wake of a highly interconnected world, assuaging and guarding against the extreme potential realities of globalization. On the other, they experience the EU as the vehicle through which they experience globalization. For this reason, globalization and its negative effects are often perceived as EU derivatives. As an outcome, strong reservations still remain about the EU.

Moreover, as nationalist tendencies and protectionism increase, so does suspicion toward the EU. Similar to globalization, the EU is, at times, perceived as an external force compromising the sovereignty of nation-states. As Hooghe and Marks point out, "opposition to European integration is couched as defense of the nation against control from Brussels.” (Hooghe and Marks 2005:423). The outcome is mistrust and a reified sense of national identity functioning as a collective mental barrier toward European integration. It is for this reason that Hooghe and Marks assert that "the strongest 
territorial identities are national, and we suspect that such identities constrain preferences concerning European integration" (Hooghe and Marks 2005:423).

The radical right has made effective use of such relapses in nationalism to reinforce and broaden its base. Political parties of the extreme- right have made considerable political gains in recent years in countries such as France, Denmark, Italy, Belgium and Austria (Hooghe and Marks 2005). Their success can be partly attributed to their rejection of European integration. Their ideological stance is premised on the principle that the $\mathrm{EU}$ is compromising the sovereignty of their respective nation-states. This outlook is particularly salient among individuals who identify strongly with their national community and who are "attached to its exclusionary norms" (Kriesi and Lachat 2004:4). In other words, Euro-skepticism is more salient among individuals with nationalistic tendencies. In fact, research suggests that national attachment has shown to be one of the strongest predictors of both European integration and opinion of globalization (O'Rourke and Sinnott 2001; Rankin 2001; Hooghe and Marks 2005; Mayda and Rodrik 2005). Due to its existential socio-historic significance, nationalism, particularly in times of uncertainty or confusion, can be retrieved in order to sustain a sense of normative collective social coherence.

While the radical right in Europe is still somewhat of a marginal movement, they have, nonetheless, demonstrated that they are a "decisive force in swaying popular opinion against Europe by mobilizing the growing uncertainties about the future of European integration among the mass public" (De Vries and Edwards 2009:6). What can be deduced is that nationalism does not only exist in the fringes and marginal movements 
of society. To this very day, it has proven to be a pervasive European phenomenon dictating attitudes and behaviors.

Therefore, in considering the literature on nationalism which suggests that the stronger a citizen's allegiance to the nation-state, the more likely he or she will be opposed to external forces that compromise the sovereignty of the nation-state, as is the case with globalization, the hypothesis is that EU citizens who place more trust in their national institutions will be more likely to have a negative opinion of globalization. 


\section{CHAPTER 4: Data and Methods}

\section{Research Design}

The analysis is conducted using data collected by the European Commission in a Eurobarometer survey of EU citizens on various issues regarding the EU, globalization and national challenges. Beginning in 1973, the Eurobarometer survey is conducted in EU member states, typically 2 to 5 times a year. The survey contains standardized items, such as questions pertaining to citizens' life satisfaction, but can also contain additional questions about various other issues, such as citizens' attitudes toward nuclear safety. The European Commission conducts the Eurobarometer survey interviews to gauge public opinion on issues so as to inform public policy.

The data on which the present study relies was collected in a 2004 Eurobarometer survey which was conducted in 15 EU member states (see Table 1). In selecting the respondents, multistage national probability sampling was conducted, yielding a total of 16,216 cases and thereby ensuring adequate number of respondents from each of 15

member states (see Table 1). Thus, demographic bias is reduced and the likelihood that the findings can be generalized is increased. The data were gathered using face-to-face survey interviews.

Using the Eurobarometer survey data is suitable for the purposes of the current study for various reasons. For one, survey interviewing is a very appropriate methodological approach when assessing individuals' opinions. This is consistently reflected in the literature (O'Rourke and Sinnott 2001; Rankin 2001; Scheve and Slaughter 2001; Lagos 2003; Mayda and Rodrik 2005; Edwards 2006). 
Moreover, a total of 16,216 cases ensures statistical power whereby more complex analyses can be conducted using a large number of variables. This imparts a great advantage, especially in considering that large, cross-national populations will be assessed.

Additionally, the rigidity of survey questionnaires ensures reliability. The questionnaire was administered in a consistent manner and had exactly the same questions and response categories across interviews. Moreover, the questionnaire had been translated into each respective country's native language. This ensures that survey questions were answered appropriately and reliably across countries and individuals.

The dataset also contains a wide array of data to work with, ranging from demographics to opinions of globalization, the economy and the EU. This imparts more options and possibilities when analyzing data. Moreover, the dataset is rich in control variables that can be included in the analysis to counter spuriousness.

By using the Eurobarometer dataset, which contains cross-national data, the research question can be addressed appropriately, which inquires about EU citizens as a whole but there is also the added advantage of observing country differences by controlling for country of citizenship. This ensures that the research question can be answered in a comprehensive and holistic manner and offer insight that is nuanced and complex.

Lastly, in using survey data to conduct the analysis, the theoretical framework the potential tension between national trust and the forces of globalization in the EU, an economic socio-political system of shared nation sovereignty consciously constructed as 
a response to globalization - can be utilized and implemented appropriately, as the dataset contains adequate EU data on both national trust and opinion of globalization.

Trust placed in national institutions is the main independent variable. It is operationalized using the following five indicators in the form of an index:

1. Trust in the national parliament

2. Trust in the national government

3. Trust in the national legal system

4. Trust in the army

5. Trust in the police

In conducting the questionnaire, the respondent was primed with the question of "I would like to ask you a question about how much trust you have in certain institutions. For each of the following institutions please tell me if you tend to trust it or tend not to trust it", followed by a list of institutions. The above five institutions were the only national institutions listed. Their injunction provides a robust measurement for the more general concept of trust in national institutions as they represent the most salient symbolic, functional and experiential dimensions of the state apparatus.

Each indicator was initially measured using three response categories: tend to trust, tend not trust and don't know (coded 1,2,3 respectively). In constructing the index, all respondents that answered "don't know" are coded as "missing". The remaining categories are coded 0 (tend not to trust) and 1 (tend to trust). Preliminary ANOVA analyses and Tukey's B tests indicate that the most appropriate cut-off point for this dichotomous variable is .5. Correlation analysis indicates high construct validity wherein 
indicators are highly correlated and can therefore be used together to construct an index. A Cronbach's alpha analysis yields a value of .776, indicating a strong relationship between indicators. The index includes respondents who answered at least 4 out of 5 questions to ensure that the independent variable is measured comprehensively.

Opinion of globalization is the dependent variable. It is operationalized in the form of an index using five questions from the Eurobarometer survey on respondents' opinion of globalization in regards to issues of national sovereignty:

1. "Overall, globalization is a good thing for (OUR COUNTRY)"

This indicator measures the dependent variable in a general and straight-forward manner. The expectation is that respondents who experience or view the phenomenon of globalization as a force that compromises the sovereignty of their respective nation-states will have less of a tendency to regard globalization as a good thing for their country.

\section{2. "Globalization represents a threat to employment in (OUR COUNTRY)"}

This indicator measures opinion of globalization specifically in regards to globalization's effects on national employment. National employment, as a subset of the global economic system, is subject to the dynamic, vigorous and, often, volatile economic conditions put forth by globalization (Castells 2006; Mills et al 2008). National employment can be threatened by globalization in various ways. A prominent theme in the literature is that globalization has had the effect of creating an interconnected international system of labor (Goff et al. 1998; McMichael 2004).This has engendered a global system of production wherein labor is fluid and mobile between countries (Mills et 
al 2008). National employment, therefore, can be threatened in the form of immigrant workers willing to work for lower wages and outsourcing - subcontracting to thirdparties such as foreign governments, companies and labor - as companies export labor and production to other countries to minimize costs. Employment can also be threatened as a result of the state's reduced capacity to protect workers' rights as it is, essentially, coerced to lower its protection standards to become more competitive in the global economy (Mills et al 2008). Moreover, national employment is particularly vulnerable to the interconnectivity of the global economic system because economic recessions or depressions in other countries can adversely affect the local economy. This compromises the state-apparatus' capacity to provide and sustain a stable system of employment. As a consequence, national economic sovereignty is compromised. The expectation is that respondents who experience globalization as a force that compromises national economic sovereignty in regards to employment will have more of a tendency to regard globalization as a threat to employment.

3. "Globalization makes it more difficult to control the quality of food products sold in (OUR COUNTRY)"

This indicator measures opinion of globalization specifically in regards to globalization's effect on the quality control of food products. As international trade intensifies, more and more food products are imported. Complications arise when countries have incongruent sanitation and quality standards. These complications can certainly be countered through the implementation of post-import food inspections but that requires the implementation 
of additional bureaucracies and expenses. The international World Trade Organization (WTO) Agreements, as finalized by the Uruguay talks of 1994, recognize that governments have the right to take post-import, pre-cautionary measures to ensure that adequate quality standards have been met. However, the WTO accords call that these measures only be implemented to the extent that they protect human, animal or plant life. So, in essence, quality control is ultimately the responsibility of the country where the food is produced. U.N. member-countries are merely encouraged, but not required, to adhere to international food quality standards (World Trade Organization 2010). Case in point is the recent investigations regarding Chinese food exports where a number of toxic substances were discovered in various food products, such as milk powder and fish (Weise and Schmit 2007; Euronews 2008). While investigations, bans and post-import regulations were implemented in response to China's toxic food exports, they were done so only after several people suffered health problems. Such occurrences make it clear that, in a globalized economic system, the state-apparatus' capacity to regulate the quality of food products in the interest of the well-being of its citizens is undermined. By implication, national sovereignty is compromised as the state is unable to fully control the quality of food products consumed within its national borders. The expectation is that citizen who regard globalization as an invasive force which compromises national sovereignty will be more likely to agree with the premise put forth by this survey question. 
4. "Globalization represents a good opportunity for (NATIONALITY) companies" This indicator measures opinion of globalization in regards to the manner by which globalization affects national companies. A global economic system imparts the opportunity for cross-border economic exchange. This can take place either in the form of trade but also in the form of outsourcing. In the case of outsourcing, national companies are not held fully accountable to the laws, regulations and limitations of their respective nation-states. For example, a trend in today's global economy is for corporations to set up offices or factories in so-called tax havens, so as to avoid paying taxes to their respective governments. The sovereignty of the nation-state is compromised due to its limited capacity in regulating its national companies and by implication its economic system. Moreover, as an outcome of the economic pressures of globalization, nation-states, in an attempt to enact what they perceive as effective liberal economic models, have been compelled to transfer many state-owned enterprises to the private sector (Mills et al 2008). The sovereignty of the nation-state is compromised due to the fact that it has, essentially, been compelled or coerced into relinquishing control over certain of its institutions. The expectation is that individuals who tend to experience globalization as an invasive force which compromises national sovereignty will have less of a tendency to regard globalization as a good opportunity for their national companies.

5. "Overall, globalization is a good thing for me"

This indicator is the most nebulous and its inclusion was a subject matter of much deliberation and theoretical reflection. The conceptualization and experience of "the self" 
in modern society is partly determined by conditions put forth by the nation-state (Mack 1983). As previously stated, in modern societies one's individual consciousness is ultimately tied to the collective consciousness, intrinsically tied to the normative order and actualized through the agent of the nation-state (Berger 1969; Smith 1993). Therefore, a compromised nation-state and its sovereignty ultimately affects the individual lived experienced. The expectation is that individuals who experience globalization as a threat to national sovereignty will have less of a tendency to regard globalization as being good for them personally. Possible exceptions to this are individuals who are conscious of their class, a phenomenon typically observed among those of higher socio-economic status. Individuals of higher socio-economic status might be conscious of the fact that globalization and economic liberalism benefits them and could thus have more of a tendency to have a positive opinion of globalization.

Each indicator is initially measured using three response categories: tend to agree, tend to disagree and don't know (coded 1,2,3 respectively). In constructing the index, all respondents that answered "don't know" are coded as "missing". The remaining categories are coded 0 (negative opinion) and 1 (positive opinion). Preliminary ANOVA analyses and Tukey's B tests indicate that the most appropriate cut-off point for this dichotomous variable is .5. Correlation analysis indicates high construct validity wherein indicators are highly correlated and can therefore be used in conjunction to construct an index. A Cronbach's alpha analysis yields a value of .706, indicating a strong relationship between indicators. The index includes respondents who answered "tend to agree" or 
"tend to disagree" to at least 4 out of 5 questions to ensure that the dependent variable is measured comprehensively.

\section{Control Variables}

As the literature suggests, the following demographic variables have been shown to be correlated with opinion of globalization and are thusly included in the analysis to counter spuriousness. The expectation is that individuals that are younger and who live in a larger locality will have more of a tendency to have a positive opinion of globalization, whereas women, the unemployed and individuals supporting the political left will have more of a tendency to have a negative opinion of globalization (O'Rourke and Sinnott 2001; Rankin 2001; Scheve and Slaughter 2001; Mayda and Rodrik 2005; Edwards 2006).

Prediction in regards to education and skill level varies according to country wealth. Individuals of higher education and skill level are generally in favor of globalization but this relationship is either weakened or reversed in poorer nations (Rankin 2001; O'Rourke and Sinnott 2001; Mayda and Rodrik 2005). For this reason, separate control variables are included for wealthier and poorer countries in regards to education, skilled manual workers and unskilled manual workers to account for the interaction of these demographic characteristics with country wealth (See Table 2). Country GDP per capita data was used to decipher an appropriate cutoff point between wealthy and poorer countries ${ }^{1}$ (United Nations 2010).

\footnotetext{
${ }^{1}$ Poorer countries include Italy, Greece, Portugal and Spain
} 
Since the current study focuses on the economic dimension of globalization it is, therefore, necessary to include some controls in regards to respondents' economic expectations. What emerges from the literature is that economic expectations can affect one's perspective on trade integration (Rankin 2001; Edward 2006). The expectation is that individuals who have negative economic expectations will tend to have a negative opinion of globalization. In operationalizing this variable, an index is constructed using the following four indicators:

1. Respondent's expectation of his or her country's economic situation in the next 12 months

2. Respondent's expectation of his or her household financial situation in the next 12 months

3. Respondent's expectation of his or her employment situation in the next 12 months

4. Respondent's expectation of his or her personal job situation in the next 12 months

A Cronbach's alpha analysis yields a value of .762, indicating a strong relationship between indicators. In constructing the index, all respondents that answered "don't know" are coded as "missing".

Attitudes toward and opinion of the EU is an issue of great theoretical and methodological importance. As previously mentioned, EU citizens experience the phenomenon of globalization through the EU. It is, therefore, prudent to include attitudes toward, and opinion of, the EU as a control variable to determine whether or not the respondents' opinions of globalization are influenced by their attitudes toward the EU. The respondents' opinion on whether his or her country has on balance benefited from 
being a member of the EU will be included in the analysis as a measure of attitude and opinion toward the EU. The expectation is that EU citizens who believe that their country has benefited from the EU will tend to have a positive opinion of globalization.

Country of citizenship is another variable that has been shown to be correlated with opinion of globalization (O Rourke and Sinnot 2001; Lagos 2003; Mayda and Rodrik 2005; Edwards 2006). Countries differ significantly in respect to their social, political and economic conditions and this might have a considerable impact on individuals' perception of globalization. Union strength, labor legislation and cultural and economic history are all factors that can influence individuals' opinion of globalization. Therefore, country of citizenship is included in the analysis as a control. For example, the Greeks have always fashioned an anti-imperialist stance, often conflated with an antiglobalization attitude and mistrust of the U.S.. Following the global economic collapse of 2008, which had a devastating effect on the country's economic and social fabric, Greek extremists, in a display of discontent, bombed the offices of JP Morgan, an American financial investment company, in Athens (Associated Press 2010).

Moreover, in an attempt to gather large enough country samples, several smallersized countries such as Luxembourg, were over-sampled and are overrepresented (See Table 1). Including country control variables eliminates potential problems with overrepresentation. The countries pertinent to the study are the 15 nation-states that were members of the EU when the survey was conducted: Belgium, Denmark, Germany, Greece, Spain, France, Ireland, Italy, Luxembourg, the Netherlands, Portugal, United Kingdom, Austria, Sweden and Finland. Each country is coded as a nominal dichotomous 
variable. Preliminary statistics show that, overall, France has the lowest mean score in regards to opinion of globalization. Therefore, France will serve as the reference category in the regression analyses to which all other countries are measured against. Odds ratio returns measure likelihood of positive opinion of globalization in relation to France. In other words, the analysis illustrates the relative likelihood of individuals from all other 14 countries, respectively, compared to those of France, to have a positive opinion of globalization.

The following tables provide further details on the various control variables that are included in the analysis. Table 1 enumerates all 15 EU countries that are included in the analysis and their respective sample sizes, populations and country averages for opinion of globalization. Table 2 lists all other control variables, providing descriptive statistics and information on how each variable is coded.

Table 1: Country Descriptive Statistics

\begin{tabular}{llcc}
\hline Country & $N$ & Mean Opinion of Globalization & Population (2004) \\
\hline Belgium & 976 & .3854 & $10,396,421$ \\
Denmark & 1019 & .5261 & $5,397,640$ \\
Germany & 2092 & .3705 & $82,531,671$ \\
Greece & 1023 & .3414 & $11,040,650$ \\
Spain & 1006 & .4220 & $42,345,342$ \\
France & 1060 & .3045 & $62,292,241$ \\
Ireland & 1046 & .4933 & $4,027,732$ \\
Italy & 1086 & .4244 & $57,888,245$ \\
Luxembourg & 458 & .3877 & 454,960 \\
Netherlands & 1056 & .5233 & $16,258,032$ \\
Portugal & 1081 & .4438 & $10,474,685$ \\
United Kingdom & 1284 & .4848 & $59,699,828$ \\
Austria & 1044 & .3809 & $8,142,573$ \\
Sweden & 996 & .5330 & $8,975,670$ \\
Finland & 1038 & .4753 & $5,219,732$ \\
\hline Source & Eur & &
\end{tabular}

Source $=$ Eurobarometer 61.0, 2004, Eurostat 2010 
Table 2: Control Variables

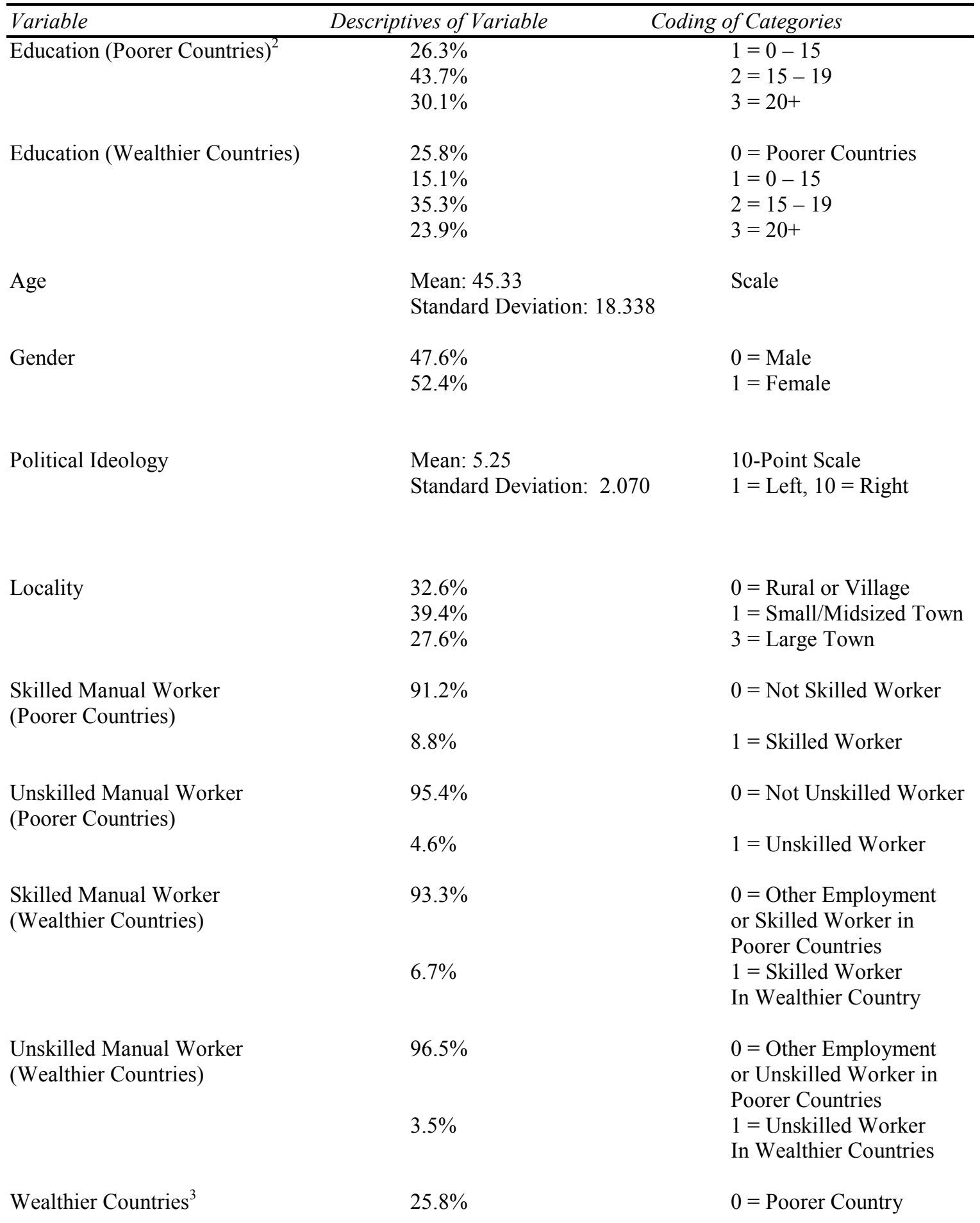

\footnotetext{
${ }^{2}$ The survey question asks: "How old were you when you stopped full-time education?"

${ }^{3}$ This variable controls for individuals who live in wealthier nations. It is included in the analysis to account for the interaction between country wealth and education and skill level.
} 


\begin{tabular}{lll} 
& $74.2 \%$ & $1=$ Wealthier Country \\
Unemployed & $93.2 \%$ & $0=$ Not Unemployed \\
& $6.8 \%$ & $1=$ Unemployed \\
& $32.6 \%$ & $0=$ Worse \\
Economic Expectations & $47.5 \%$ & $1=$ Same \\
& $19.9 \%$ & $2=$ Better \\
& $38 \%$ & $0=$ Not Benefited \\
EU Benefit & $62 \%$ & $1=$ Benefited \\
\hline
\end{tabular}

Source= Eurobarometer 61.0, 2004

\section{Limitations}

The following section deconstructs the current study's limitations. Explanation is given for the various challenges that were encountered and how they were dealt with during data analysis.

The manner in which the education variable was operationalized initially in the dataset is problematic. The survey questionnaire asks the respondents how old they were when they stopped their full-time education. Those who were attending school full-time at the time of the interview were coded as " 00 ". This presents various challenges and limitations. Most importantly, the age at which one stops their full-time education is not necessarily reflective of their level of education. The educational path that people choose to take is not always linear in that they attend junior school, then high-school, then college and then post-graduate school. For example, some individuals choose to join the workforce after high-school and continue their higher education years later. While keenly aware of the limitations of this variable, it is, nonetheless, included in the analysis as a loose measure of education. The objective is not necessarily to produce exact numbers that are representative of reality but, rather, to observe general tendencies in the 
population. In choosing to use this variable in the analysis, it had to be modified accordingly to increase, as much as possible, its validity. Therefore, units that were coded as " 00 " were recoded to "age", in an attempt to include in the analysis individuals who were full-time students at the time of the interview and to decrease the number of missing cases.

The manner in which almost all variables were coded presents further limitations. Most variables contained a "don't know" category. This category had to be discarded as "missing" throughout the analysis for two reasons. First, it did not inform the theoretical framework. For example, a "don't know" answer in regards to a question on trust in the national government does not produce any data that is useful in answering the research question of whether trust placed in national institutions correlates with EU citizens' opinion of globalization. Furthermore, a "don't know" category is symbolically nebulous and, therefore, cannot be coded and organized in a manner that is linear or ordinal. For example, consider the following survey question: "Generally speaking, do you think that (OUR COUNTRY)'s membership of the European Union is...?", the response categories for which are "a bad thing", "neither good or bad", "a good thing" and "don't know". A "don't know" answer does not indicate, in any way whether the respondent feels good, bad or neutral in regards to the question and, therefore, cannot be included in the ordinal sequence of categories when conducting the analysis. Therefore, all the "don't know" categories were coded as "missing". This creates several problems.

First, as the analysis becomes more complex and more variables are included, the number of missing cases increases. The final logistic regression model, for example, 
includes only half of the initial number of respondents. Second, while a "don't know" category does not indicate directional attitude or neutrality, it is nonetheless representative of individuals' attitude toward a certain issue and can produce insightful findings. Third, excluding the "don't know" category is problematic when collapsing multiple indicators into a single index. The reason for this is that individuals who answered "don't know" to any one of the indicator questions, are excluded from the entire index. This produces a problematically large number of missing cases.

However, in assessing the construction of the indices, preliminary descriptive statistics and histograms show that "don't know" answers occur at random. Histograms were constructed that included respondents that answered either all of the questions, 4 out of 5 questions and 3 out of 5 questions for both the dependent and independent variable indices. What was clearly evident was that the distribution of the data was minimally affected in the exclusion of individuals who answered "don't know" to 1 or 2 questions. In other words, there is nothing unique about those individuals as the rest of their answers are congruent with the population at large. Therefore, in excluding them from the analysis, the distribution, trends and tendencies of the data do not appear to be affected. Moreover, in constructing both the independent and dependent variable indices, only those respondents who answered "don't know" to 2 or more of 5 questions are excluded. This was done to strike a balance between constructing variables that are measured comprehensively and reducing the number of missing cases. Furthermore, the initial number of respondents is 16,212 ensuring an adequate number of cases even after the 
"don't know" categories have been coded as missing. For example, the final regression model includes an ample 7446 cases.

There are also limitations in regards to the operationalization of the dependent variable. As already stated, the dependent variable of opinion of globalization is operationalized using five questions from the Eurobarometer survey in regards to issues of national sovereignty. While those five indicators are adequate in operationalizing opinion of globalization for the purpose of the study, they, nonetheless, fall short in reflecting the theoretical and actual complexity of the subject matter. Ideally, the dependent variable would have been operationalized in a comprehensive manner, taking into account various other dimensions and nuances of opinion of globalization in regards to issues of national sovereignty. For example, the survey questionnaire could have included questions explicitly in regards to economic sovereignty, such as:

- 'Do you believe that globalization compromises the government's capacity to effectively control the national economy?"

- "Do you believe that globalization represents a threat to our local businesses?"

- "Do you believe that globalization contributes to economic instability?"

Another limitation of the dataset is the fact that it does not contain data for all current EU member states. The data was collected in 2004, shortly before the EU enlargement process which acceded 12 countries (see Appendix for a list of all current EU member states). The findings are therefore pertinent to the EU population prior to the 2004 enlargement process. Conceivably, the inclusion of all $27 \mathrm{EU}$ member states could affect the findings. This is due to the fact that the recently acceded population is 
considerably different in regards to socio-historic experience compared to Western Europe, especially in considering the fact that many of the newly-acceded countries formerly belonged to the Soviet Union. Nonetheless, the current study provides useful insight on EU citizens' opinions and attitudes that should be taken into consideration regardless of whether the newly acceded countries are not included in the analysis, especially in considering that the majority of the EU population and the most influential countries, including the EU founders, are included. Let us now proceed to the analysis. 


\section{CHAPTER 5: Analysis and Findings}

The analysis begins with an examination of the descriptive statistics of the independent and depending variable. As Chart 1 illustrates, the majority of EU citizens tend to trust their national institutions $(56.6 \%)$ and, as Chart 2 illustrates, tend to have a negative opinion of globalization $(57.8 \%)$ in regards to issues of national sovereignty. These findings are consistent with the theoretical prediction, in that there would be more of a tendency for citizens to trust their national institutions and less of a tendency to have a positive opinion of globalization in regards to issues of national sovereignty.

\section{Chart 1: Trust in National Institutions}

(\%)

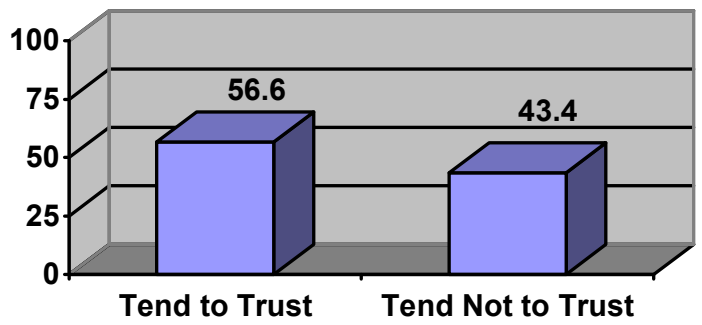

Source: Eurobarometer 61.0, 2004

$\mathrm{N}=14,470$

\section{Chart 2: Opinion of} Globalization (\%)

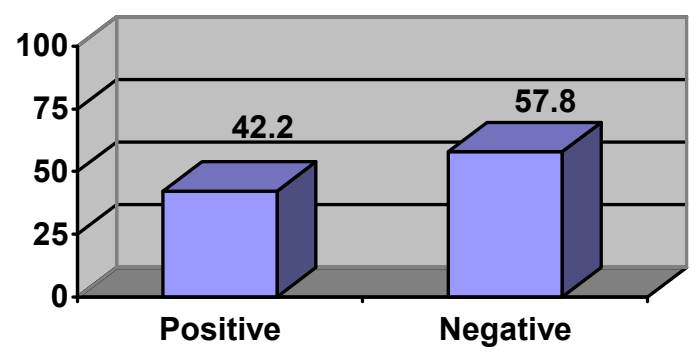

Source: Eurobarometer 61.0, 2004 $\mathrm{N}=11,847$ 
A bivariate analysis is then conducted, pertaining directly to the research hypothesis, comparing trust placed in national institutions with opinion of globalization. As Table 3 illustrates, there is a tendency among both groups of EU citizens who trust and do not trust their national institutions to have a negative opinion of globalization in regards to issues of national sovereignty. However, EU citizens who trust their national institutions have more of a tendency to have a positive opinion of globalization. For example, $49.6 \%$ of EU citizens who trust their national institutions have a positive opinion of globalization, while only $33.6 \%$ of EU citizens who do not trust their national institutions have a positive opinion of globalization.

Table 3: EU Citizens' Opinion of Globalization, By National Trust (\%)

\begin{tabular}{|c|c|c|c|}
\hline & & \multicolumn{2}{|c|}{ National Trust } \\
\hline & & Trust & Don't Trust \\
\hline Opinion of Globalization & $\begin{array}{l}\text { Positive } \\
\text { Negative }\end{array}$ & $\begin{array}{l}49.6 \\
50.4\end{array}$ & $\begin{array}{l}33.6 \\
66.4\end{array}$ \\
\hline Total & & 100 & 100 \\
\hline
\end{tabular}

Source= Eurobarometer 61.0, 2004

$\mathrm{p}<.001$

$\mathrm{N}=10,946$

What follows is a regression analysis. Since the dependent variable is a dichotomous variable, logistic regressions are used, establishing 2 models predicting opinion of globalization. The analyses yields some interesting findings presented in Table 4. The main independent variable, trust in national institutions, is shown to predict opinion of globalization in both regression models. In Model 2, after country control variables are included, trust in national institutions yields a statistically significant $(\mathrm{p}<$ 
.001) coefficient of .396 . The odds ratio value suggest that individuals who trust their national institutions are 1.486 times as likely to have a positive opinion of globalization in regards to issues of national sovereignty compared to those who do not trust their national institutions.

Several demographic characteristics also predict opinion of globalization. In respect to age, Model 2 suggests that as one's age increases their likelihood of positive opinion of globalization decreases. Specifically, for every year of increase in age, respondents are $.006(1-.994)$ times less likely to have a positive opinion of globalization $(\mathrm{p}<.001)$. These findings are consistent with the literature. Compared to older individuals, younger adults are more exposed to the global media, the internet and foreign languages and travel more. This contributes to the development of a supranational conception of identity which, in turn, posits globalization in a more favorable view.

In respect to political ideology, the findings suggest that individuals on the "right" of the political ideology spectrum are more likely to have a positive opinion of globalization. As Model 2 suggests, for every unit of increase toward the "right" spectrum, respondents are 1.069 times as likely to have a positive opinion of globalization $(\mathrm{p}<.001)$. From a cultural standpoint, these findings are unexpected. The political right has demonstrated a tendency to rhetorically reject globalization, especially in regards to cultural and political issues. However, from an economic standpoint these findings are not surprising as the political right has traditionally and consistently favored liberal economic practices. 
Unemployment and gender also predict opinion of globalization. In Model 2, unemployed respondents are $.214(1-.786=.214)$ times less likely to have a positive opinion of globalization compared to those who are not $(\mathrm{p}<.05)$. The gender variable yielded an odds ratio value of .876 indicating that women, compared to men, are .124 (1 $.876=.124)$ times less likely to have a positive opinion of globalization in regards to issues of national sovereignty $(\mathrm{p}<.05)$. In other words, both the unemployed and women have more of a tendency to have a negative opinion of globalization. These finding are consistent with both the theoretical and the empirical literature on globalization.

A prevalent theme in the literature is that individuals who are socially and economically vulnerable because of globalization, as is the case with women and the unemployed, are less likely to have a positive opinion of globalization because they feel victimized by its invasive effects, particularly in regards to the economy (O'Rourke and Sinnott 2001; Steve and Slaughter 2001; Mayda and Rodrik 2005). In regards to gender, additional statistical analyses of income reveal that income disparities persist within the EU. For example, $19 \%$ of women, compared to $14.7 \%$ of men fall within the lowest income bracket. In contrast, $18.9 \%$ of men, compared to $15.8 \%$ of women, fall within the highest income bracket. Notable is the fact that, in recent decades, there has been an official and coordinated effort on behalf of the EU to reduce the gender gap (Verloo 2006; Meier and Lombardo 2008; Walby 2008). However, academics point to the fact that while the gender gap has been curtailed in recent years, gender disparities still persist within the EU (Walby 2008; Occhionero and Nocenzi 2009). This has been attributed to the EU's to failure to address the particularity of gender inequalities, compared to other 
types of inequalities such as income, particularly as an outcome of structural mechanisms, the state and the private sphere (Verloo 2006). Others cite the EU's official framing of gender as the culprit, which constructs gender-differentiated citizens, presenting women as mothers, workers and victims (Meier and Lombardo 2008). As Meier and Lombardo suggest, the promotions of "legal gender equality and acknowledging the existence of gender obstacles to the enjoyment of an equal citizenship for women, are not by definition translated into policy initiatives transformative of traditional gender roles" (Meier and Lombardo 2008:489).

In regards to unemployment, interestingly, further statistical analyses show that individuals who are unemployed are also more likely to mistrust their national institutions. For example, $54.7 \%$ of those who are unemployed do not trust their national institutions compared to the $45.3 \%$ who do. This indicates that, counter to the literature, nation-states, whose legitimate representatives are its national institutions, are not necessarily assessed in opposition to globalization. In essence, in the wake of the economic uncertainties of globalization, EU citizens do not necessarily revert to the more traditional institutions of the nation-state.

Education also predicts opinion of globalization. As Model 2 illustrates, individuals with greater levels of education that live in poorer countries are $.128(1-.872$ $=.128)$ times less likely to have a positive opinion of globalization $(\mathrm{p}<.05)$. On the contrary, individuals with greater levels of education that live in wealthier nations are 1.254 times as likely to have a positive opinion of globalization $(\mathrm{p}<.05)$. These findings are consistent with the literature, in that individuals who are more educated and live in 
wealthier countries tend to have a positive opinion of globalization because they are in a better position to benefit from the global economic system. On the other hand, individuals who are more educated but that live in poorer countries, which are generally more vulnerable to the effects of globalization, tend to have a negative opinion of globalization because they are conscious of their vulnerability.

Similar tendencies are observed in regards to skill level. As Table 4 illustrates, skilled manual workers from wealthier countries tend to have a positive opinion of globalization while skilled manual workers from poorer countries tend to have a negative opinion of globalization. As Model 2 suggests, skilled manual workers from wealthier nations are 1.869 times as likely to have a positive opinion of globalization $(p>.05)$ while skilled manual workers from poorer countries are $.392(1-.608=.392)$ times less likely to have a positive opinion of globalization $(\mathrm{p}<.05)$. Again, these findings are consistent with the literature which suggests that individuals who are of higher skill level and live in wealthier countries tend to have a positive opinion of globalization because they are in a better position to benefit from the global economic system. On the other hand, skilled workers from poorer countries tend to have a negative opinion of globalization because they are conscious of their potential vulnerability to the global economic system.

Economic expectations also predict opinion of globalization in regards to issues of national sovereignty, yielding a statistically significant coefficient of .269 $(p<.001)$ and an odds ratio value of 1.309 in Model 2. The findings indicate that the better a respondent's economic expectations are the more likely he or she will have a positive 
opinion of globalization. These findings are consistent with the literature which consistently demonstrates that economic expectations are an important predictor of opinion of globalization. Globalization has created a global economic system that is highly dynamic, volatile and uncertain. Individuals who are impacted by globalization's economic uncertainty and who, therefore, have a negative outlook on their economic future are less likely to regard globalization in a positive light, to which they attribute their lack of future economic prosper.

The most interesting finding regards respondents' opinion of the EU which in Model 2 yields a coefficient of $.969(\mathrm{p}<.001)$. Respondents who are of the opinion that, overall, their country has benefited from being a member of the EU are 2.636 times as likely to have a positive opinion of globalization in regards to issues of national sovereignty. In other words, EU citizens who believe that they have benefited from the EU are more likely to have a positive opinion of globalization. These findings are congruent with the theoretical framework put forth in the present study. EU citizens experience the phenomenon of globalization through the vehicle and the lens of the EU, functioning as a steering force in the wake of this invasive and unpredictable phenomenon. As suggested by the literature, one of the main functions of the EU is to mitigate the negative effects of the globalized economy through economic, intergovernmental and socio-cultural integration. The outcome is a united and highly structured economic, socio-political bloc, highly empowered by its collective strength in the wake of globalized realities. It, therefore, makes perfect sense that EU citizens' 
opinion of globalization is filtered through their country's experience of the EU. But what about the individual countries themselves?

As previously mentioned, country odds ratios represent likelihood of positive opinion of globalization compared to France, which, in preliminary analyses yielded the lowest mean in regards to the dependent variable. In reference to Model 2, the countries that yielded the highest odds ratios, indicating likelihood of positive opinion of globalization, by no surprise, are Denmark (2.547), the Netherlands (3.341), Sweden (5.259), Ireland (2.586) and the U.K. (3.086). In other words, these are the countries whose citizens have more of a tendency to have a positive opinion of globalization. The reasons behind these findings are clear.

Countries such as Denmark, Sweden and the Netherlands come from a socialdemocratic tradition where governments are actively involved in the national economic system. Traditionally, the economic policies enacted in these countries were done to ensure economic equity and worker protection (Mills et al. 2008). As an outcome, their citizens have been buffered from the negative economic effects of globalization and, therefore, tend to have a more positive opinion of globalization.

Ireland, at the time the survey was conducted, had benefited greatly from both its EU membership and globalization. Due to its originally below average standard of living, Ireland received large amounts of economic help from other EU member states as part of the EU's structural adjustment funds, which aim to "level the playing field" by redistributing money from the wealthier nations to the poorer ones. This, in conjunction with the economic opportunities imparted by globalization have, in recent years resulted 
in unprecedented economic growth and have elevated the standard of living of Ireland above the EU average. It is, therefore, by no surprise that Irish citizens are amongst the staunchest supporters of globalization.

In considering the findings concerning the U.K., there is theoretical ambiguity. The U.K. has always been highly skeptical of the EU and has consistently demonstrated exceptionalism. Evidence of this is the U.K.'s refusal to join the EU's monetary union in using a single currency, the Euro. Moreover, the U.K. has emerged from a highly nationalistic tradition and, even in recent years, has been highly resistant and wary of transnational agreements or external forces which could potentially compromise its national sovereignty. In this regard, the findings are quite surprising. However, the U.K. has also emerged from a historical tradition rooted in colonialism and free market capitalism. No empire has contributed to the global proliferation of capitalism as much as the British Empire has and, what is currently the U.K., has benefited greatly from its history of global colonial capitalism. Furthermore, ever since the administration of Margaret Thatcher, neo-liberal ideals and economic policies have dominated the political atmosphere of the U.K. Therefore, it is by no surprise that U.K. citizens have a positive opinion of globalization, even in regards to issues of national sovereignty. Let us now proceed to an interpretation of the findings based on the comprehensive conception of globalization presented in Chapter 2 and the theoretical framework presented in Chapter 3. 
Table 4. Logistic Regression Models Predicting Positive Opinion of Globalization

\begin{tabular}{|c|c|c|}
\hline Variable & Model 1 & Model 2 \\
\hline Trust in National Institutions & $\begin{array}{l}.407 * * \\
(1.502)\end{array}$ & $\begin{array}{l}.396 * * \\
(1.486)\end{array}$ \\
\hline \multicolumn{3}{|l|}{ Demographics } \\
\hline Gender (Female) & $\begin{array}{l}-.155^{*} \\
(.857)\end{array}$ & $\begin{array}{l}-.132 * \\
(.876)\end{array}$ \\
\hline Age & $\begin{array}{l}-.006 * * \\
(.994)\end{array}$ & $\begin{array}{l}-.006 * * \\
(.994)\end{array}$ \\
\hline Education (Poorer Countries) & $\begin{array}{l}-.146^{*} \\
(.864)\end{array}$ & $\begin{array}{l}-.137 * \\
(.872)\end{array}$ \\
\hline Education (Wealthier Countries) & $\begin{array}{l}.287 * * \\
(1.332)\end{array}$ & $\begin{array}{l}.226 * \\
(1.254)\end{array}$ \\
\hline Political Ideology (Right) & $\begin{array}{l}.058 * * \\
(1.060)\end{array}$ & $\begin{array}{l}.066 * * \\
(1.069)\end{array}$ \\
\hline Locality (Urban) & $\begin{array}{l}-.022 \\
(1.022)\end{array}$ & $\begin{array}{l}.026 \\
(1.027)\end{array}$ \\
\hline Unemployed & $\begin{array}{l}-.316^{*} \\
(.729)\end{array}$ & $\begin{array}{l}-.241 * \\
(.786)\end{array}$ \\
\hline Skilled Manual Worker (Poorer Countries) & $\begin{array}{l}-.436 * \\
(.647)\end{array}$ & $\begin{array}{l}-.497 * \\
(.608)\end{array}$ \\
\hline Skilled Manual Worker (Wealthier Countries) & $\begin{array}{l}.489 * \\
(1.631)\end{array}$ & $\begin{array}{l}.626^{*} \\
(1.869)\end{array}$ \\
\hline Unskilled Manual Worker (Poorer Countries) & $\begin{array}{l}-.101 \\
(.904)\end{array}$ & $\begin{array}{l}-.319 \\
(.727)\end{array}$ \\
\hline Unskilled Manual Worker (Wealthier Countries) & $\begin{array}{l}.206 \\
(1.229)\end{array}$ & $\begin{array}{l}.357 \\
(1.429)\end{array}$ \\
\hline Wealthier Countries & $\begin{array}{l}-.196 \\
(.822)\end{array}$ & $\begin{array}{l}-1.507 \\
(.221)\end{array}$ \\
\hline Economic Expectations & $\begin{array}{l}.284 * * \\
(1.328)\end{array}$ & $\begin{array}{l}.269 * * \\
(1.309)\end{array}$ \\
\hline Country Benefited from EU & $\begin{array}{l}.795 * * \\
(2.215)\end{array}$ & $\begin{array}{l}.969 * * \\
(2.636)\end{array}$ \\
\hline Countries (France is Reference Country) & & \\
\hline Belgium & & $\begin{array}{l}.261 \\
(1.298)\end{array}$ \\
\hline Denmark & & $\begin{array}{l}.935 * * \\
(2.547)\end{array}$ \\
\hline Germany & & $\begin{array}{l}.480 * * \\
(1.617)\end{array}$ \\
\hline Greece & & $\begin{array}{l}-1.262 \\
(.283)\end{array}$ \\
\hline Spain & & $\begin{array}{l}-.727 \\
(.484)\end{array}$ \\
\hline Ireland & & $\begin{array}{l}.950 * * \\
(2.586)\end{array}$ \\
\hline Italy & & $\begin{array}{l}-.325 \\
(.722)\end{array}$ \\
\hline Luxemburg & & $\begin{array}{l}.278 \\
(1.321)\end{array}$ \\
\hline Netherlands & & $\begin{array}{l}1.206 * * \\
(3.341)\end{array}$ \\
\hline
\end{tabular}


$\begin{array}{ll}\text { Portugal } & -.202 \\ & (.817)\end{array}$

U.K.

$1.127 * *$

(3.086)

Austria

$.541 * *$

Sweden

(1.718)

Finland

$1.660 * *$

(5.259)

$.849 * *$

(2.337)

Constant

Number of Cases

$-1.215^{* *}$

$-.740$

2 Log Likelihood

7572

7572

$9714.172 * * \quad 9375.659 * *$

Note: Unstandardized logistic coefficients with odds ratios in parentheses.

$* \mathrm{p}<.05 * * \mathrm{p}<.01$

Source $=$ Eurobarometer 61.0, 2004 


\section{CHAPTER 6: Discussion}

The current study inquires whether trust in national institutions correlates with EU citizens' opinion of globalization in regards to issues of national sovereignty. It was hypothesized that EU citizens who place more trust in their national institutions are more likely to have a negative opinion of globalization. The hypothesis was generated in consideration of both the historic literature on nationalism and the globalization literature, both of which show a staunch correlation between national attachment and rejection of forces external to the nation-state that compromise national sovereignty. The findings suggest that the hypothesis does not hold true.

Overall, the findings show that EU citizens have a tendency to trust their national institutions and have a negative opinion of globalization in regards to issues of national sovereignty. However, in examining and contrasting those who trust their national institutions to those who do not, we find that there is more of a tendency to have a positive opinion of globalization among EU citizens who do trust their national institutions. The findings can be interpreted as follows.

Historically, nationalism's value system i.e. patriotism, historical destiny and perceived ethnic superiority, and its structural components i.e. national institutions were intrinsically tied. This tendency was observed in all European countries, particularly those under totalitarian regimes that surfaced during the 1930s, which had the overwhelming, if not the absolute, countenance of their citizens. During this time most European countries were taken over by authoritarian governments, as was the case with Italy, Germany, Spain, Portugal, Poland, Hungary and so forth (Goff et al. 1998). During this era of extreme nationalism, citizens not only pledged full support to the nation-state, 
but they also legitimated the state's use of violence to repress and oppress opposition that challenged the nation, the state or its institutions.

There is the possibility that the interplay of the EU and globalization has generated a culture wherein nationalism as a world view and experience has been reconfigured so that the structural components of the nation-state, such as its institutions, are differentiated from its nationalistic value system. Therefore, trust in national institutions is not necessarily an attitude informed by, and intrinsically tied to, nationalism's value system which rejects forces external to the nation-state. As an outcome, trust in national institutions is not posited against globalization.

This differentiation of the nation-state's structural components from its nationalistic value system may occur because of the economic and social benefits that the EU imparts. The EU is an economic socio-political system consciously constructed to effectively manage globalization and to mitigate its negative effects, particularly in regards to the economy. An example of this is the EU's Structural and Cohesion funds, which aim to reduce development and economic disparities between member states (Europa 2009). These funds represent $35 \%$ of the EU's budget and its main contributors are the EU's richest and most prosperous member states and are diverted to less prosperous member states in an attempt to reduce economic inequalities and to promote further integration (Europa 2009). To fully understand the EU's importance in providing and sustaining economic benefit and its subsequent impact on the nation-state, one has to consider the conditions under which the nation-state emerged. 
Among other things, the nation-state's genesis has its roots in economic interests, both in terms of the elites which sought to further empower their social and economic status through the nation-state, but also through the general populace which sought economic and social stability through the nation-state. However, the nation-state's capacity to impart these economic benefits has been adversely affected because of globalization. But within the EU, because globalization is systematically managed, the nation-state and its citizens are not only empowered economically but are also in a better position to reap the economic benefits of globalization. In light of this, it is reasonable to assert that because of the tremendous economic benefits that the EU puts forth, through its managing of globalization, national attachment is not necessarily experienced in opposition to globalization. Rather, the nation-state, via the EU, might be experienced as an empowering entity, efficacious in providing economic sustainability. Perhaps, more than anything else, what enables the EU to effectively manage globalization is the fact that it has been configured in a system of shared-national sovereignty.

As previously mentioned, the EU is a an intergovernmental and supranational system of governance, whose member states are interconnected via reciprocal sociodemocratic processes premised on the rule of law, security and justice, peace and stability, diversity and economic and social solidarity, configured in a socio-political system of pooled sovereignty (McCormick 2005; Europa 2009). The EU's unique sociopolitical structural configuration has generated a social order wherein member states and their respective societies are intrinsically tied, co-dependent and cooperatively managing and making decisions about their social, economic and political future. As McCormick 
suggests, "Increasingly, national and European interests have become indistinguishable from each other" (McCormick 2005:111).

Moreover, there has been a shift in power and authority from the member states to the EU (McCormick 2005). In various cases this results in EU law, policy and the collective priorities of its member states taking precedence over that of individual member states. In this sense, national sovereignty within the EU takes on a supranational dimension as it extends beyond national borders and, most importantly, is experienced as such. This is not only due to the fact that the EU has made a conscious effort in promoting the value of supranationalism, but also due to the fact that supranationalism and inter-governmentalism is institutionalized. An example of this is the European Parliament whose parties are comprised of multinational representatives. In this sense, the European Parliament is the first parliament with parties of multinational constituents.

In essence, the EU has generated the conditions wherein national attachment is not necessarily posited against globalization, since the national experience takes on an international and transnational dimension. Globalization, as mediated through the EU, is experienced and essentially becomes, at least to some extent, a part of the nation-state. The EU can be considered a contained and managed form of globalization, rigidly structured between its member states, wherein national institutions, via EU mechanisms, extend and function beyond the nation-state. This structured and contained form of globalization, that is nonetheless economically, socially and politically fluid between EU member states, might have an effect on the way EU citizens view and experience globalization in general. This is due to the fact that their experience of globalization is 
one that is contained, managed, beneficial and most importantly, one that extends the nation-state in an economic, socio-political system beyond its borders in a system of shared national sovereignty. It is in this way that the nation-state is experienced as part of a broader globalized order and thusly not posited in opposition to globalization.

The EU has also contributed to the development of a European socio-political consciousness wherein the nation-state is experienced not as separate, but as a part of the EU. Empirical data confirm this assertion. A question pertaining to national identity on the Eurobarometer survey interview asked the respondents whether they considered themselves as "national only", "national and European” or "only European". Interestingly, the plurality (46\%) of the respondents, consider themselves as both national and European. As Hooghe and Marks suggest, "European integration reinforces multiculturalism. It erodes exclusionary norms of 'us' and 'them' that are deeply rooted in the creation of European national states" (Hooghe and Marks 2005:423).

This emergence of European supranational consciousness has had the effect of weakening the traditional, rigid conception of national identity which had been particularly prevalent and salient in Europe during the $19^{\text {th }}$ and first half of the $20^{\text {th }}$ century. National identity is experientially and intrinsically tied to the nation-state and, by implication, to the nation-state's sovereignty. An emergence of a supranational consciousness inevitably weakens and relativizes national identity and, consequently, nationalistic and rigid conceptions of national sovereignty. This experiential social paradigm shift, even though it initially occurs within the framework of the EU, wherein national identity and, by implication, national attachment is relativized, allows for an 
experience of globalization that is not posited in opposition to the nation-state. The nation-state and its sovereignty might be challenged by globalization, but this challenge is not necessarily perceived and interpreted through a rigid nationalistic world outlook which cannot accept a compromised nation-state. Rather, supranationalism, even though in this case initially emerges within the EU, tends toward an experience wherein the individual and his or her identity are tied to a broader, global social order.

The EU has also redefined the symbolic and experiential meaning of citizenship. As mentioned in Chapter 3, globalization has had the effect of compromising the experience of the national citizen due to the fact that it undermines the state apparatus' efficacy and capacity to provide to its citizens economic and social stability and sustainability. In essence, citizens are left to fend for themselves against a volatile and increasingly dynamic global economic system. The EU has managed to mitigate the negative effects of globalization by granting supranational efficacy and rights to its citizens. This occurs on two levels.

It occurs on the internal level wherein EU citizens' legal rights extend beyond national borders. For example, EU citizens have the capacity to work, travel, become educated, invest and file law suits across national lines. It also occurs on the intergovernmental and supranational level. For example, during the global economic collapse of 2008, the EU functioned as a coordinator so as to effectively deal with the economic woes in an inter-governmental and supranational fashion. Taking the British response to the financial crisis as a model, the EU launched initiatives aimed at curbing the crisis across the rest of Europe by proposing sales tax cuts, tackling the housing crisis and 
offering relief to carmakers (Euronews 2008b). The EU also grants greater efficacy to its citizens on the international level by functioning as a representative and advocate for both its member states and its citizen constituents, such as in international meetings and functions like the G8 summits.

This has generated conditions wherein citizenship is experienced on a supranational level. As Sassen suggests, "citizenship is at least partly and variably shaped by the conditions within which it is embedded" (Sassen 2006:280). In altering the structural, experiential, functional and symbolic realities of citizenship, the EU has redefined it. Citizenship, "even if situated in institutional settings that are 'national', is a possibly changed institution if the meaning of the national itself has changed" (Sassen 2006:280).

Ever since the advent of modernity, citizenship has been intrinsically tied to the nation-state and conventionally experienced as separate to anything external. However, within the EU, citizenship is intrinsically tied to a social and political order constituted by a multiplicity of nation-states. The EU citizen is a part of this reality. Therefore, citizenship within the EU is not solely tied to the nation-state. Rather, citizenship, through the framework of the EU, takes on an international character and becomes an international experience. This has had the effect of compromising rigid and nationalistic conceptions of citizenship that had been prevalent in Europe throughout the $19^{\text {th }}$ and first half of the $20^{\text {th }}$ century. In elevating the experience of the citizen to the supranational level, and reinforcing it with supranational protection against globalization, the EU has generated conditions where citizenship is slowly being detached from its traditional 
counterpart - the nation-state - and is becoming a part of a broader, but nonetheless contained and effectively managed, order. What reinforces this experiential shift of citizenship from the national to the supranational level is the EU's success in providing a framework where the functions of citizenship become more effective in the framework of globalization. In doing so, it has reinforced the nation-states' function of granting and sustaining citizenship. For this reason national attachment is not necessarily experienced in opposition to globalization.

In considering the above, what clearly transpires is that EU citizens' experience of globalization is funneled through their experience of the EU. It is by no surprise, then, that the greatest predictor of positive opinion of globalization is whether the respondent feels that overall, his or her country has benefited from its EU membership. This interplay between opinion of globalization, opinion of the EU and national attachment is structured through the conditions put forth by the EU, such as the opening up of economies, free travel and migration, inter-country work mobility and the supranational institutionalization of democracy. It is also structured through the EU's function as a buffer against the negative effects of globalization by granting agency and collective efficacy to its citizens. Empirical data confirm this assertion. When asked who they trusted the most to deal with the effects of globalization, choosing from a list of institutions, organizations and countries, the plurality of EU citizens $(30.6 \%)$ chose the EU.

In essence, much in accord with the theoretical framework put forth in Chapter 3, the EU can be thought of as a highly structured mechanism, intended to strategically 
manage globalization and to mitigate its negative effects. This is achieved by facilitating sustainable and beneficial economic conditions and by effectively utilizing the opportunities of globalization while diminishing its threats. As discussed earlier, the EU was initiated on the basis of economic incentives and considerations, the purpose of which was to establish economic solidarity among member states in an attempt to increase collective economic efficacy as a deterrent of war. As economic integration furthered, so did the need for political and social integration. The underlying structures that enable the EU to be efficacious in its promotion of economic benefit in the context of globalization, is its political configuration, premised on the principle of shared sovereignty, and its social integration, which, even though implicit in nature, provides additional support for its economic and political structures. This results in the development of socio-economic conditions which elevate the experience of the nationstate to the supranational level.

Much like the EU, the emergence of nation-states can be attributed, partly, to economic incentives and considerations. However, with the advent and the intensification of globalization, nation-states were increasingly ineffective in providing economic stability and sustainability. The EU has managed to empower the nation-state's economic functions by integrating them to a broader economic order that is actively reinforced by transnational cooperation on the political level. As an outcome, the power and efficacy of the individual nation-states increase as they become part of a collective. This consideration is of particular importance in an era of globalization as global issues and challenges, such as climate change, have the capacity to extend beyond national borders 
and, therefore, require supranational cooperation. Thus, supranationalism, in the context of globalization, can be thought of as an especially efficacious tool in dealing with the challenges of the nation-state. A global order necessitates global cooperation. In light of the above, it is prudent to address and consider potential broader implications. 


\section{CHAPTER 7: Conclusion}

The present study was formulated in consideration of the challenges, as well as the opportunities of globalization. History, as well as the current state of global affairs, has taught us that the phenomenon of globalization can generate conditions of potential conflict and social and political turmoil. However, globalization also has the capacity to contribute to international cooperation, economic and social sustainability and supranationalism to the benefit of citizens. The overarching question of the present study is under what conditions is globalization experienced not necessarily in opposition to the nation-state.

This formulation was informed not by conviction or ideological support for globalization but, rather, as a response to the fact that globalization is a phenomenon that has become an existential milieu. It is therefore our duty and responsibility as academics, as citizens and as social agents to address the challenges and potentials of globalization. The EU represents the potential of globalization.

This assertion is by no means a naïve call of judgment. Rather, it is one based on empirical research and relevant theoretical frameworks. There is no doubt that the potential of the EU is tainted by its relative, but nonetheless substantial shortcomings. The challenges of the EU are widely cited, ranging from its incapacity to effectively deal with immigration, to its citizens' perceived democratic deficit and lack of transparency (Habermas 1998b; McCormick 2005). But these challenges are outweighed by the potential of the EU as well as its achievements, particularly in creating and sustaining peace in Europe and actively dealing with the challenges of globalization. Above all, the EU's strength lies in its intergovernmental and transnational institutionalization of 
democracy, sharing of national sovereignty and joint global social and political steering (Giddens 2000). This has generated conditions wherein national attachment is not necessarily posited against globalization. On the contrary, counter to other systems of social organization, national attachment in the EU is one of the greatest predictors of positive opinion of globalization. This is where the EU's potential lies.

The EU represents a potential future model of social, economic and political organization in a globalized world, through its unique capacity to manage globalization and impart a beneficial and sustainable economic system by reconfiguring democracy, the nation-state and citizenship and elevating them to a supranational level (Giddens 2000). Giddens sees the EU "as forging a way that could, and very likely will, be followed in other regions too" (Gidden 2000:98). Its establishment and achievements have been lauded from the very same academics that have called for the creation of supranational democratic structures and processes (Habermas 1998b; Giddens 2000). As Habermas suggests, politics should "follow the lead of the markets by constructing supranational political agencies. Europe, in transition toward the European Union provides a suitable example" (Habermas 1998b:413).

The potentiality for economic integration in a system of supranational democracy, particularly one that is modeled after the EU, has attracted considerable academic and political interest in recent years, as globalization and its challenges intensify. This is reflected in the fact that the EU and its institutional structures have been the subject of 
rigorous and systematic study both within and outside Europe ${ }^{4}$. Most importantly, the EU, as a potential model for social, economic and political organization, has propelled other countries to consider the possibility of supranational democracy. This is reflected in a recent proposal to create a South Asian Union, modeled after the EU (South Asian Union 2005).

Certainly, this paper is by no means an unqualified endorsement of the EU. The potentiality of the EU as a future model for managing globalization and of transnational democracy is a subject matter that warrants further study and reflection. The direction proposed is the following. The present, as well as previous studies, have demonstrated the potential of the EU model as a system for social, economic and political organization in a globalized world. In light of this, greater academic, political and civic focus should be placed on the EU. Specifically, what need to be studied are the institutional processes of the EU that contribute to and sustain its highly integrated economic system, peace and supranationalism. Moreover, further study needs to be conducted on how, and in what capacity, these processes can be applied in economic socio-political frameworks outside of Europe. Lastly, the limitations of the EU, as well as its shortcomings and challenges need to be addressed so as to potentially propose solutions to optimize its transnational economic socio-democratic model.

The EU's greatest potential contribution stems from its ability to build and sustain peace, derived from its capacity to effectively manage globalization and reconfigure national attachment. This assertion is of great significance when understood in light of

\footnotetext{
${ }^{4}$ For example, see the following journals: European Union Politics, Journal of European Public Policy, Asia-Pacific Journal of EU Studies
} 
the fact that Europe is the birth place of nationalism, the greatest contributor to $19^{\text {th }}$ and $20^{\text {th }}$ century conflict, and the battleground and genesis of two world wars. It is an astounding fact that after a century and a half of bloodshed and two world wars, Europeans are able to not only live in peace, but also to co-exist in a supranational democratic system. Herein exists the EU's potential contribution to the broader global community. 


\section{RESOURCES}

Alderson, Arthur S. and Francois Nielsen. 2002. "Globalization and the Great U-Turn: Income Inequality Trends in 16 OECD Countries" American Journal of Sociology 107:1244-99

Anastasiou, Harry. 2008a. "The EU as a Peace Building System: Deconstructing Nationalism in an Era of Globalization." The International Journal of Peace Studies 12(2):31-50.

Anastasiou, Harry. 2008b. The Broken Olive Branch: Nationalism, Ethnic Conflict and the Quest for Peace in Cyprus. Volume I: The Impasse of Ethnonationalism. Syracuse, New York: Syracuse University Press.

Anderson, Benedict. 1983. Imagined Communities: Reflections on the Origin and Spread of Nationalism. New York, New York: Verso

Associated Press. 2008. "Iceland Teeters on the Brink of Bankruptcy" MSNBC, October $8^{\text {th }}$. Retrieved May 9, 2010

(http://www.msnbc.msn.com/id/27065178/ns/business-world_business/)

Associated Press. 2010. "JPMorgan Bombing: Bomb Explodes at Bank Offices in Athens" The Huffington Post, February $16^{\text {th }}$. Retrieved February 29, 2010 (http://www.huffingtonpost.com/2010/02/16/jp-morgan-bombing-bombex_n_464128.html)

Batty, David. 2009. "Iran: Twitter Becomes Focal Point of Protests” The Guardian, December $28^{\text {th }}$. Retrieved May 9, 2010 (http://www.guardian.co.uk/world/blog/2009/dec/28/iran-protests-twitter)

Berger, Peter. 1969. The Sacred Canopy: Elements of a Sociological Theory of Religion. United States of America: Anchor Books

Berger, Peter. 2000. "Four Faces of Global Culture" Pp. 417-427 in Globalization and the Challenges of a New Century, edited by Patrick O'Meara, Howard D. Mehlinger and Matthew Krain. Bloomington, IN: Indiana University Press.

Boserup, Ester. 2007. Woman's Role in Economic Development. United Kingdom: Cromwell Press 
Buchholz, Sandra. 2009. "Life Courses in the Globalization Process: The Development of Social Inequalities in Modern Societies" European Sociological Review 25(1):5371

Castells, Manuel. 1996. The Rise of the Network Society. Malden, Massachusetts: Blackwell Publishers Inc.

CBS News. 2009. "Obama Takes Aim At Tax Havens, Loopholes" CBS News, May $4^{\text {th }}$. Retrieved Feb 8, 2010 (http://www.cbsnews.com/stories/2009/05/04/politics/main4988677.shtml?source $=$ RSSattr=Business 4988677 )

Cohen, Joseph Nathan and Miguel Angel Centeno. 2006. "Neoliberalism and Patterns of Economic Performance, 1980-2000" The Annals of the American Academy of Political and Social Science 606(1):32-67

Deutsch, Karl W. 1966. Nationalism and Social Communication: An Inquiry into the Foundations of Nationality. Cambridge, Massachusetts: MIT Press.

De Vries, Catherine E. and Erica E. Edwards. 2009. “Taking Europe to Its Extremes: Extremist Parties and Public Euroscepticism" Party Politics 5(1):5-28

Dogan, Mattei. 1994. "The Erosion of Nationalism in the West European Community." The International Journal of Sociology 24(1):31-61

Durkheim, Emile. 1915. The Elementary Forms of Religious Life. London (Orig. French ed., 1912)

Edwards, Martin S. 2006. "Public Opinion Regarding Economic and Cultural Globalization: Evidence from a Cross-national Survey" Review of International Political Economy 13(4):587-608

Ellul, Jacques. 1964. The Technological Society. United States of America: Alfred A. Knopf

Eurobarometer. 2003. "Globalisation." Retrieved November 28, 2008 (http://ec.europa.eu/public_opinion/flash/FL151bGlobalisationREPORT.pdf) Eurobarometer. 2004. "The European Union Globalization and the European Parliament, February-March 2004" Retrieved October 15, 2008 (http://www.icpsr.org) 
Euronews. 2006: "Commission Recommends Turkey EU Accession Slow Down”

Euronews, November $29^{\text {th }}$. Retrieved May 10, 2010

(http://www.euronews.net/2006/11/29/commission-recommends-turkey-euaccession-slowdown/)

Euronews. 2008. "China milk scandal: Brussels proposes controls" Euronews, September $25^{\text {th }}$. Retrieved Feb 5, 2010 (http://www.euronews.net/2008/09/25/china-milkscandal-brussels-proposes-controls/)

Euronews. 2008b. "EU Launches Three-Pronged Attack on Economic Crisis" Euronews, November $26^{\text {th }}$. Retrieved April 20, 2010 (http://www.euronews.net/2008/11/26/eu-launches-three-pronged-attack-oneconomic-crisis)

Euronews. 2009. "Minaret Debate Angers Swiss Muslims" Euronews, November $19^{\text {th }}$. Retrieved May 5, 2010 (http://www.euronews.net/2009/11/19/minaret-debateangers-swiss-muslims/)

Europa. 2009. "The Official Website of the European Union" Retrieved December 1, 2008 (http://europa.eu/index_en.htm)

European Navigator. 2010. "Address given by Lionel Jospin on the future of an enlarged Europe (Paris, 28 May 2001)" Retrieved Feb 2, 2010 (http://www.ena.lu/addressgiven-lionel-jospin-future-enlarged-europe-paris-28-2001-020005644.html)

Eurostat. 2010. "Data Explorer: Population by sex and age on 1. January of each year

" Retrieved May 19, 2010 (http://appsso.eurostat.ec.europa.eu/nui/submitViewTableAction.do)

European Parliament. 2009. European Parliament calls for the end of tax havens, Press Release April 24, Retrieved Jan $19^{\text {th }}$ 2010, from (http://www.europarl.europa.eu/sides/getDoc.do?language=EN\&type=IMPRESS\&reference $=20090422$ IPR54272)

Falk, Richard. 1999. Predatory Globalization: A Critique. USA: Blackwell Publishers Inc.

Feron, Elise. 2004. "Anti-globalization movements and the European agenda" The European Journal of Social Science Research 17(2):119-127

Gabel, Matthew and Guy Whitten. 1997. "Economic Conditions, Economic Perceptions, and Public Support for European Integration" Political Behavior 19(1):81-96. 
Gabel, Matthew. 1998. "Economic Integration and Mass Politics: Market Liberalization and Public Attitudes in the European Union" Journal of Political Science 42(3):936-953

Ganguly-Scrase. Ruchira and Gillian Vogl. 2008. "Ethnographies of Gendered Displacement: Women's Experiences in South Asia Under Neo-liberal Globalisation" Women Studies International Forum 31:1-15

Garrett, Geoffrey. 1998. Partisan Politics in the Global Economy. New York. Cambridge University Press.

Goff, Richard et al. 1998. The Twentieth Century: A Brief Global History. USA: McGraw Hill.

Habermas, Jurgen. 1998a. "Beyond The Nation State" Peace Review 10(2):235-239

Habermas, Jurgen. 1998b. "The European Nation-State: On the Past and Future of Sovereignty and Citizenship" Public Culture 10(2):297-416

Habermas, Jurgen. 2002. "Toward a European Political Community” Society 39(5):58-61

Hooghe, Liesbet and Gary Marks. 2005. "Calculation, Community and Cues: Public Opinion on European Integration" European Union Politics 6(4):419-443

Jackson, David. 2009. "Obama hammers GM; Chrysler, Fiat deal takes shape" USA Today, March 20 $0^{\text {th }}$. Retrieved, May 5, 2010 (http://www.usatoday.com/money/autos/2009-03-30-bailout-wagoner_N.htm)

Jamieson, Lynn. 2005. Orientations of Young Men and Women to Citizenship and European Identity, 2004. European Commission. Retrieved May 2, 2010 (http://www.sociology.ed.ac.uk/youth/final report.pdf)

Jung, Jai Kwan. 2008. “Growing Supranational Identities In a Globalising World? A Multilevel Analysis of the World Values Survey" European Journal of Political Research 47:578-609

Kohut, Andrew, and Richard Wike. 2008. "Assessing Globalization: Benefits and Drawbacks of Trade and Integration." Harvard International Review 30(1):70-74.

Krasner, Stephen D. 2001. Problematic Sovereignty: Contested Rules and Political Possibilities New York, USA: Columbia University Press 
Kriesi, Hanspeter and Romain Lachat. 2004. "Globalization and the Transformation of the National Political Space: Switzerland and France Compared”, Presented at a workshop on the analysis of political cleavages and party Competition, April 2-3, Duke University, Durham, NC.

Lagos, Marta. 2003. "World Opinion: Global Trends in Culture and Trade" International Journal of Public Opinion Research 15(3):335-351

Leonard, Mark. 2006. Why Europe Will Run The $21^{\text {st }}$ Century. Great Britain: Public Affairs.

Mack, John. 1983. "Nationalism and the Self: An Essay on the Collective Narcissism of Everyday Life" The Psychohistory Review 11:47-69

Mayda, Anna Maria and Dani Rodrik. 2005. "Why Are Some People (And Countries) More Protectionist than Others" European Economic Review 49:1393-1430

McCormick, John. 2005. Understanding the European Union: A Concise Introduction. New York, USA: Palgrave Macmillan.

McMichael, Philip. 2004. Development and Social Change: A Global Perspective. London, UK: Sage Publications Ltd.

Meier, Petra and Emanuela Lombardo. 2008. "Concepts of Citizenship Underlying EU Gender Equality Policies" Citizenship Studies 12(5):481-493

Merino, Noel. 2008. The European Union: Opposing Viewpoints Detroit, Michigan: Greenhaven Press

Meschi, Elena and Marco Vivarelli. 2009. “Trade and Income Inequality in Developing Countries" World Development 37(2):287-202

Mills, Melinda et al. 2008. "Converging Divergences?: An International Comparison of the Impact of Globalization on Industrial Relations and Employment Careers" International Sociology 23(4):561-595

NZ Herald. 2001. "World Leaders United In Condemnation” NZ Herald, September $12^{\text {th }}$. Retrieved Jan 22, 2010 (http://www.nzherald.co.nz/world/news/article.cfm?c id=2\&objectid=216547)

O'Rourke, Kevin H. and Richard Sinnott. 2001. "The Determinants of Individual Trade Policy Preferences: International Survey Evidence” Brookings Trade Forum. 
Rankin, David M. 2001. "Identities, Interests, and Imports" Political Behavior 23:351376

Sassen, Saskia. 1996. "Toward a Feminist Analytics of the Global Economy" Indiana Journal of Global Legal Studies 4:7-41

Sassen, Saskia. 2000. "Women's Burden: Counter Geographics of Globalization and the Feminization of Survival" Journal of International Affairs 53:503-24

Sassen, Saskia. 2006. Territory, Authority, Rights: From Medieval to Global Assemblages. Princeton, New Jersey: Princeton University Press.

Scheve, Kenneth F. and Mathew J. Slaughter. 2001. Globalizatgion and the Perceptions of American Workers. Washington: Institute of International Economics.

Smith, Anthony D. 1993. "Ties that Bind." LSE Economic and Political Science Magazine, 5(1):8-11

South Asian Union. 2005. "South Asian Union: A Proposal to Build a South Asian Union (SAU)" Retrieved April 20, 2010

(http://www.southasianunion.net/about sau.php).

Stiglitz, Joseph E. 2002. Globalization and its Discontents. USA: W.W. Norton \& Company, Inc.

The African Economic Community. 2010. "Treaty Establishing the African Economic Community" Retrieved March 31, 2010 (http://www.africaunion.org/root/au/Documents/Treaties/Text/AEC_Treaty_1991.pdf)

The Association of South East Asian Nations. 2010. Retrieved March 21, 2010 (http://www.aseansec.org/)

The Pew Global Attitudes Project. 2007. "World Publics Welcome Global Trade But Not Immigration." Retrieved November 28, 2008 (http://pewglobal.org/reports/pdf/258.pdf)

Toffler, Alvin. 1980. The Third Wave. USA: William Morrow and Company, Inc. Occhionero, Marisa F. and Mariella Nocenzi. 2009. "Gender Inequalities: The Integrated Approach to the Gender Dimension in Europe" International Review of Sociology 19(1):155-169 
United Nations. 2009. "Conference of the Parties: Draft Decision" Copenhagen Accord, December $7^{\text {th }}$ to $18^{\text {th }}$. Retrieved February 2, 2010 (http://unfecc.int/resource/docs/2009/cop15/eng/107.pdf)

United Nations. 2010. "United Nations Statistics Division: National Accounts" Retrieved June 11, 2010 (http://unstats.un.org/unsd/snaama/dnllist.asp)

United States Department of Agriculture. 2010. "North American Free Trade Agreement (NAFTA)" Retrieved May 9, 2010 (http://www.fas.usda.gov/itp/policy/nafta/nafta.asp)

Verloo, Mieke. 2006. "Multiple Inequalities, Intersectionality and the European Union" European Journal of Women's Studies 13(3):211-228

Walby, Sylvia. 2008. "Policy Developments for Workplace Gender Equity in a Global Era: The Importance of the EU" Review of Policy Research 12(1):45-64

Wallerstein, Immanuel. 1999. The End of the World As We Know It: Social Science for the $21^{\text {st }}$ Century. Minneapolis, MN: University of Minnesota Press.

Weise, Elizabeth and Julie Schmit. 2007. "FDA limits Chinese food additive imports" USA Today, May $1^{\text {st }}$. Retrieved Feb 5, 2010 (http://www.usatoday.com/money/industries/2007-04-30-chinese-importsusat N.htm)

Wood, D.M and Birol Yesilada. 2006. The Emerging European Union. New York, USA: Longman.

World Trade Organization. 2010. Retrieved Feb 19 2010, (http://www.wto.org/english/docs e/legal e/ursum e.htm\#bAgreement)

Zakaria, Fareed. 2006. "The Decline and Fall of Europe" Newsweek, February $20^{\text {th }}$.

Zarroli, Jim. 2010. "Fed to Examine Goldman Role in Greek Debt Crisis" NPR, February 25. Retrieved May 19, 2010 (http://www.npr.org/templates/story/story.php?storyId=124087299) 


\section{APPENDIX}

EU member states when survey was conducted: Austria, Belgium, Denmark, Finland, France, Germany, Greece, Ireland, Italy, Luxemburg, the Netherlands, Portugal, Spain, Sweden, United Kingdom

All current EU member states: Austria, Belgium, Bulgaria, Cyprus, Czech Republic, Denmark, Estonia, Finland, France, Germany, Greece, Hungary, Ireland, Italy, Latvia, Lithuania, Luxemburg, Malta, the Netherlands, Poland, Portugal, Romania, Slovakia, Slovenia, Spain, Sweden, United Kingdom 